\title{
THE HOUR OF BIRTH
}

\section{A STUDY OF THE DISTRIBUTION OF TIMES OF ONSET OF LABOUR AND OF DELIVERY THROUGHOUT THE 24-HOUR PERIOD}

\author{
BY \\ ENID CHARLES \\ Department of Medical Statistics, University of Birmingham, and Queen Elizabeth Hospital, Birmingham
}

\section{(1) INTRODUCTION}

Whether variations with respect to frequency of births from hour to hour within the course of the day are such as we might expect in any situation in which an immensely complex congeries of circumstances conspires to reproduce the characteristic features of a random sampling system, or whether there is a systematic trend indicative of some predominant agency contributory to a manifest diurnal cycle, are questions of interest both at the administrative level, and from the viewpoint of the biologist in quest of a deeper understanding of the mechanism of labour. The issue has provoked not a few descriptive statistical inquiries of which the outcome has been inconclusive up to date. For reasons which follow, this is not surprising.

(i) To undertake any such inquiry with profit it is first necessary to be clear about the operational intention vis $\dot{a}$ vis the method of selecting relevant data. If the end in view is the concern of the administrator with the hours of work of the physician or of the midwife, we shall wish to base our conclusions on a representative sample of all births. If our aim is to clarify the processes which initiate healthy parturition, we shall wish to exclude all induced labours and all labours associated with pathological conditions. In that event, the time of onset rather than the time of delivery is most relevant to a useful decision; but results of enquiries at different times in the same place, or in different places at the same time, might well prove to be discordant in virtue of different fertility levels, if special circumstances attendant on delivery of the first-born effectively mask a manifest trend among later births.

(ii) If we take cognizance of the foregoing considerations regarding the selection of data, and more especially of the need to compare time of delivery with time of onset, we must also allow for the possibility of new sources of observational error. To date the time of onset we must rely on the testimony of the mother with a prospect familiar to statisticians in contact with census enumeration, viz. clumping of data around fashionable numbers. Furthermore, we shall need to be clear that our criterion of onset is consistent. It will thus be apparent that the customary appeal to tests for goodness of fit will throw little light on a conclusive answer. Any such test employed to date in the context of this enquiry invokes the unique null hypothesis that the distribution is rectangular, subject to randomwise variation due to error as such or to natural variation. We need not take sides in the current controversy concerning the rationale of test procedure, if we here insist that any source of systematic error comparable to clumping of the sort mentioned will prejudice the prescribed interpretation of the test result.

The rejection of the customary null hypothesis does not answer the question: is there a diurnal cycle sensu stricto? For its rejection is consistent with an infinitude of alternative hypotheses for a reason which it is pertinent to recognize when assembling data of the sort under consideration, regardless of what attitude we adopt to test procedure in general or the $\chi^{2}$ test in particular. To speak of a diurnal rhythm implies a day-to-day regularity with respect to events which occur within one and the same 24-hour period. The mere existence of a peak in the course of the latter in a single pool of data based on different days does not prove that such a regularity exists. Since we must pool our data in some way, some chronological subdivision of the pool, such as the seasonal split discussed below, is therefore prerequisite to conclusive demonstration that the same pattern recurs on different days.

(iii) It is less obvious to the statistician who is not en rapport with recent advances in the study of the sex hormones, that the method of pooling as well as the method of selecting the data of such an inquiry is eminently relevant to the outcome. If a trend exists in any sense of the term intelligible to the physiologist, we must seek its origin among either or both of two categories of agencies which may conceivably reinforce or conceivably neutralize one another. Physical events such as light and temperature impose on the material environment in which parturition occurs a diurnal rhythm, and the normal routine of work, meals, and sleep imposes a diurnal rhythm on the social environment. The pattern of neither the one nor the other is consistent throughout the year. Superimposed on each diurnal pattern of 
external change are seasonal regularities which may again augment or minimize a systematic trend arising from the sequence of physical or social events incident to the completion of the 24-hour period.

The implications of the possible interplay of seasonal and diurnal events have hitherto received no consideration in this type of inquiry; and they raise issues rarely if ever explicitly recognized in inquiries into seasonal variation of vital statistics in general. It is therefore pardonable to comment on them more fully at this stage, the more so because they will dictate the pooling procedure adopted in what follows. We may first recall that the uterus is subject both to direct reflex control via its autonomic innervation, and to neurohumoral control via its blood supply. The former is presumptively more especially relevant to the impact of the diurnal cycle of social routine, the latter more especially to the impact of the diurnal cycle of physical milieu.

That the stresses and strains of social routine on the mother throughout the day-time when she is near full-term are not identical in different parts of the calendar year would be too trivial for comment, were it not for the custom of recording seasonal variation of vital statistics by an arbitrary 4-fold split of the calendar year (in contradistinction to the school year, the inland revenue year, and so forth), regardless of the annual lay-out of agencies of presumptive aetiological relevance to the topic. That a seasonal change may mask or magnify a diurnal trend which has its origin in the physical environment is also a possibility which we cannot dismiss lightly, if we reflect on two considerations:

(a) the established major role of the pituitary anterior lobe as a pace-maker of the female reproductive cycle;

(b) the established role of light with respect to reflex activation of both lobes of the gland and the antagonistic influence of light at opposite ends of the visual spectrum as effective visual stimuli.

From the point of view last stated, we must indeed distinguish between both qualitative and quantitative differences affecting the diurnal cycle of light and darkness at two levels. The exposure of the individual to artificial illumination, and ceteris paribus to relatively more visible radiation of long wave length, will be greatest at the winter solstice, when the same is true of daylight. Conversely, the influence of long wave length visible radiation, if any, will be least at the summer solstice; and around the equinoxes conditions relevant to both quantity and quality: of solar radiation are identical. Thus comparison of data referable to comparable periods on either side of each equinox offers a unique opportunity of distinguishing the effects of the solar component of the diurnal rhythm of external events from any effects uniquely traceable to the diurnal rhythm of social routine. Owing to the institution of daylight saving, British solar mean time is in advance of the social calendar by approximately one hour on September 21, the two being in step on March 21, and the correction for converting mean time into true solar time at these two dates is trivial.*

Thus a diurnal trend predominantly attributable to light should be recognizable in British data referable to a compact community by a shift of the diurnal peak or the diurnal minimum of just over three-quarters of an hour when we collate records based on data in the vicinity of the two equinoxes. Contrariwise, concordant results referable to the two periods, confirming the real existence of a diurnal period if the peak times are identical, would also point to the influence of agencies referable to the social calendar, i.e. to the rhythm of social routine.

The issue with which this communication deals has lately come under discussion in the correspon- 8 dence columns of the British Medical Journale (Simpson, 1952). According to editorial commont several statistical inquiries during the last 40 years? have indicated little, if any, significant difference between the numbers of births taking place between 6 a.m. and 6 p.m., and between 6 p.m. and 6 a.m., the difference in favour of night-time births being at most 2 to 5 per cent. A later correspondent gave figures from Lancashire showing a 10 per cent. excess of births in the 12-hour period 11 p.m. to 11 a.m. A study (de Porte, quoted by Hill, 1948) of births in New York State during the decade 1915-25 by 3-hourly periods gave a distribution of times almost identical with the Lancashire figures, both showing that 54 per cent of births occur between midnight and 3 a.m.

The results quoted are for all births including those in which there has been medical or surgical induction of labour or assisted delivery. The writer is not aware of any comparable data about time of onset of labour throughout the 24-hour period. It thus seemed that an examination of fresh data from a more analytical standpoint might be of interest.

\footnotetext{
* On March 21, Greenwich mean noon occurs at 12.4 p.m. Greenwich solar time. On September 21 it occurs at 11.52 a.m. Greenwich wich solar time. On September 21 it occur
solar time. The difference is 12 minutes.

solar time. The difference is 12 minutes.
ti.e. a community referable to an area within which variation with reference to longitude is negligible.
} 
The time of birth can be thought of as the result of two sets of processes, those which initiate labour, and those which determine the duration of labour.* Presumably, at each stage, different types of influences may be predominant. For reasons stated, the time of onset of labour, though far less susceptible to accurate observation, should show more clearly than the time of delivery whether in fact variations attributable to one or the other have a detectable effect. The method here adopted is therefore first to examine the distribution of times of onset, and then to explore, in conjunction with duration of labour, the distribution of times of delivery. To define more precisely in what circumstances, if any, a diurnal variation is detectable, and with a view to its interpretation, births were first classified as referable to primigravidae or multigravidae, as domiciliary or institutional, and as taking place at a given time of year. In the first instance, as is described in more detail below, all births accompanied by some circumstance likely to affect the onset or course of labour were excluded. To provide at the same time information directly relevant to the issue as it presents itself to the administrator, Tables will also be given covering live and still births of all types.

\section{(2) MATERial AND Methods}

The Public Health Department of the City of Birmingham receives, for resident live and still births occurring in the city, an Antenatal and Delivery Record completed by the midwife in the case of domiciliary births, and by a member of the hospital staff in the case of hospital births. These records are copied on to the Health Visitors' Records, and the original delivery records were made available to us by the courtesy of the Department of Maternity and Child Welfare.t They call explicitly for the date and exact time of onset and delivery. The duration of labour to the nearest hour is computed from these times and recorded by the office. Some hospital forms, however, give the duration of labour to the nearest minute or hour together with the time of delivery. These delivery records have been received for live births since January 1949 and for stillbirths since January 1951. Rendition has not been complete and is estimated at about 90 per cent.

\footnotetext{
* In this inquiry, duration of labour includes the first and second stages only. It ends with the delivery of the foetus.

$t$ In an inquiry of this sort, it does not always happen that the investigator can speak with first-hand knowledge of the reliability of rendition and methods of recording the data employed. During her tenure as Chief Statistical Officer to the City Corporation, at the request of the Department of Maternity and Child Welfare, the author designed new records (Charles, 1951) and supervised, on behalf of the department, the inauguration of a new machinery of rendition.
}

for live births during the period covered by the inquiry. About half the missing records are those of nursing-home and private-doctor patients and these constitute a possible source of bias. Among the delivery records available, time of onset or delivery was not given or was ambiguous in about 6 per cent. Rendition was complete for stillbirths in 1951 , in that a record existed, but the absence of some material particular reduced the usable records to 93 per cent. of the total. The total number of live and still births for which times of onset and delivery were tabulated exceeded 16,000 .

Of the two times recorded, the exact moment of delivery has legal significance, and the method of obtaining the information suggests that in general the times recorded should be reasonably accurate. In the case of babies born before the arrival of a medical attendant, information is hearsay and hence less accurate. The times of onset are much less reliable. The onset of labour is defined in Birmingham practice, both domiciliary and hospital, as the first painful contraction of the uterus followed by others at regular intervals. Yet it has seemed that hospitals may sometimes regard rupture of the membranes as constituting onset. In addition to ambiguities surrounding the actual event, the observer is the mother only and hence the record is a stage further removed from first-hand recording. As a result there are indications in part of the data of clumping at even hours. Whether in addition biased errors occur can only be determined, if at all, from the results.

The delivery records contain particulars of plurality, the antenatal record, the type of labour, and the condition of the infant. As indicated above, a number of records were excluded where circumstances seemed likely to affect materially the onset or course of labour. Those excluded were:

(a) stillbirths;

(b) second twins, second and third stillbirths;

(c) antenatal complications: toxaemia, positive Wasserman, rubella, non-toxic ante-partum haemorrhage, pyelitis, hydramnios, endocrine dysfunction;

(d) medical or surgical induction or delivery;

(e) all presentations other than vertex;

$(f)$ all congenital malformations of the infant.

The records were complete in respect of plurality, and very nearly so in respect of type of labour, presentation, and congenital malformations. The antenatal record was less complete, and some of the named complications may have been missed, but these, together with the complications not rejected, 
were few in number. The association between antenatal complications and medical or surgical intervention, etc., ensured that the more complete screening of the rest of the record would eliminate most of the missed antenatal complications. Hence the cases analysed, hereafter referred to as "selected cases", consist very largely of pregnancies and labours free from any pathological disturbance up to the time of delivery, except for the minor common complaints, anaemia, and varicose veins.

The selected cases fall into two groups. First all the 1950 and 1951 cases falling in the 4-weekly periods round the solstices and equinoxes were examined with a view to possible effects of light intensity. As numbers of births fall off towards the end of the year, these were supplemented by all remaining cases in August-September and NovemberDecember. Parity was obtained for the second set of cases. This item is not given on the delivery records so each record had to be matched with its corresponding punch-card in the files of the Maternity and Child Welfare Department. The considerable labour involved unfortunately limited the numbers available for analysis by parity. All records were sorted as domiciliary or institutional births, the former including "born before arrival" and ambulance deliveries.

\section{(3) TIME OF ONSET}

(a) All Selected Cases.-As a background to the differences found among different types of births, Table $I$ and Fig. 1 show the percentage
TABle I

PERCENTAGE ONSET OF LABOUR BY TIME OF DAY SELECTED CASES

\begin{tabular}{c|c|c|c}
\hline Time of Day & Percentage & Time of Day & Percentage \\
\cline { 2 - 3 } 12 Midnight & 5.2 & 12 Noon & 2.7 \\
1 a.m. & 6.6 & 1 p.m. & 2.4 \\
2 a.m. & 7.4 & 2 p.m. & 3.7 \\
3 a.m. & 6.1 & 3 p.m. & 3.1 \\
4 a.m. & 5.6 & 4 p.m. & 3.3 \\
5 a.m. & 3.9 & 5 p.m. & 3.2 \\
6 a.m. & 4.5 & 6 p.m. & 3.9 \\
7 a.m. & 3.9 & 7 p.m. & 3.1 \\
8 a.m. & 3.7 & 8 p.m. & 3.5 \\
9 a.m. & 3.5 & 9 p.m. & 3.9 \\
10 a.m. & 3.0 & 10 p.m. & 5.3 \\
11 a.m. & 2.8 & 11 p.m. & 5.7 \\
\hline
\end{tabular}

distribution by times of onset of labour of all births selected as described above. The raw data for Table I and other percentage tables of time of onset are given in Appendix Table A (p. 59). The distribution shows a clearly marked peak at 2 a.m. to $3 \mathrm{a} . \mathrm{m}$. In the 6-hour period 11 p.m. to $5 \mathrm{a} . \mathrm{m}$., 37 per cent. of labours began compared with the expected 25 per cent. The greatest difference between night and day is shown by taking the 12-hour period 9 p.m. to 9 a.m. with 62 per cent. of all onsets, as compared with 38 per cent. of onsets between 9 a.m. and 9 p.m. The point of minimum onset is less clearly marked but occurs in this distribution at 1 p.m. to 2 p.m. There are minor peaks at 2 p.m. 6 p.m., 11 p.m., and 6 a.m. To a small extent these peaks reflect the clumping at even numbers found ino part of the data but there are indications of 4-hourly periodicity, the significance of which is obscure. To show the distribution without these

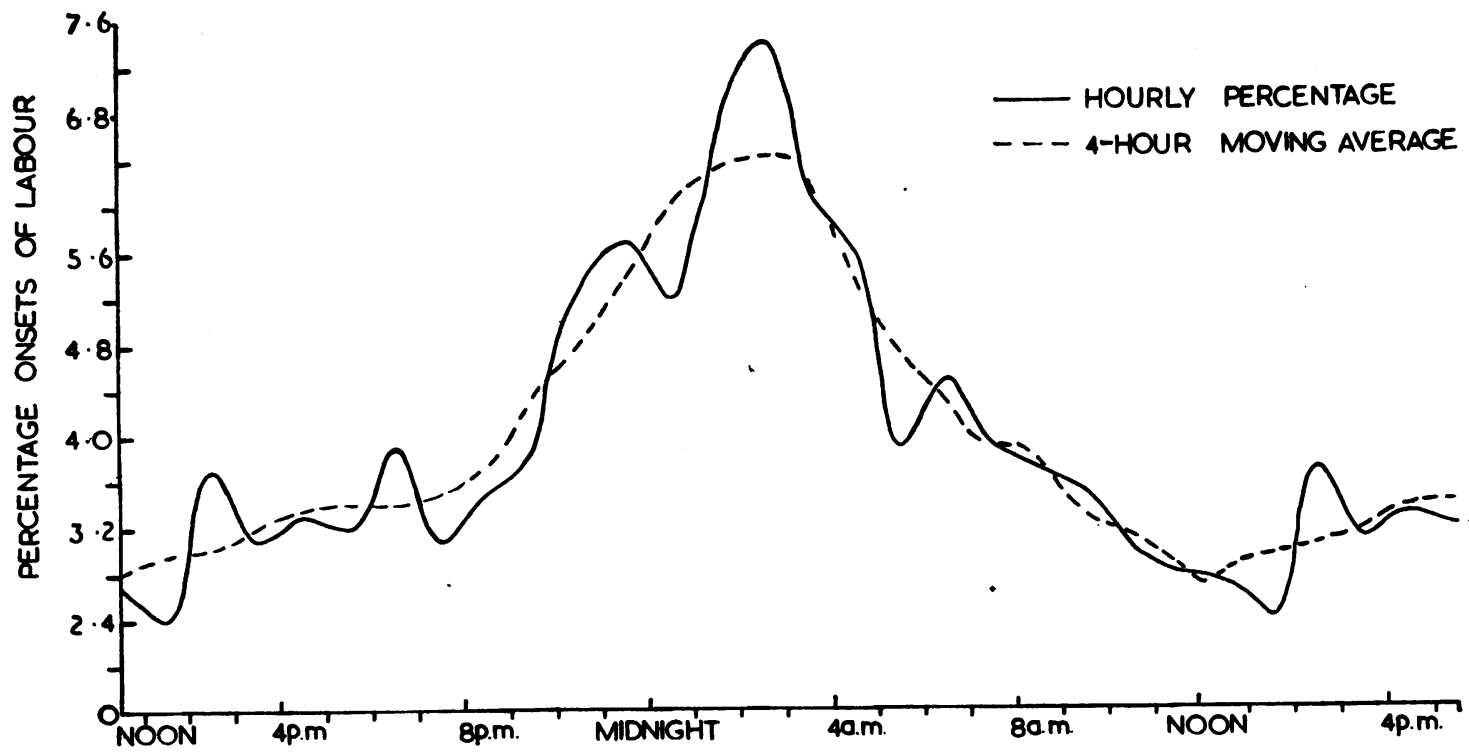

Fig. 1.-Percentage distribution of times of onset of labour in all selected births. 
subsidiary peaks, Fig. 1 gives a 4-hourly moving average. The main features of Fig. 1 are found in all the sub-classes of this group of cases. Apart from irregularities which may be due to small numbers, they differ, as will be seen, in the flatness of the curve and in the proportions of onsets which occur before the 2 a.m. peak.

(b) Parity.-Appendix Table A exhibits four groups of data for each of which we have separate records referable respectively to primigravidae and to others. Parity in this inquiry means number of previous live and still births, so that primigravidae are those women who have not previously had a pregnancy resulting in a viable foetus.

All eight distributions show a peak similar to that in Fig. 1. In six it falls in the same place, 2 a.m. to 3 a.m., and in the other two it falls between midnight and 1 a.m., and between 1 a.m. and 2 a.m. The minimum, being less clearly defined and involving sometimes very small numbers, is much more scattered, but all fall in the daytime, between 8 a.m. and 10 p.m. The greatest difference between the unsmoothed distributions is shown by the domiciliary onsets in August (Fig. 2). The differences between primigravidae and others are most simply shown by percentages in 6-hour periods (Table II). In the periods of maximum and minimum onset, 11 p.m. to 5 a.m. and 11 a.m.
TABLE II

PERCENTAGE TIMES OF ONSET BY PARITY6-HOUR PERIODS

\begin{tabular}{|c|c|c|c|c|c|}
\hline \multirow{2}{*}{ Time } & \multirow{2}{*}{ Parity } & \multicolumn{2}{|c|}{ Domiciliary } & \multicolumn{2}{|c|}{ Institutional } \\
\hline & & $\begin{array}{c}\text { Aug. } \\
\text { Per cent. }\end{array}$ & $\begin{array}{l}\text { Nov. } \\
\text { Per cent. }\end{array}$ & $\begin{array}{c}\text { Aug. } \\
\text { Per cent. }\end{array}$ & $\begin{array}{c}\text { Nov. } \\
\text { Per cent. }\end{array}$ \\
\hline $\begin{array}{l}11 \text { p.m. to } \\
5 \text { a.m. }\end{array}$ & $\begin{array}{l}\text { Primigravidae } \\
\text { Multigravidae }\end{array}$ & $\begin{array}{l}48 \cdot 1 \\
36 \cdot 4\end{array}$ & $\begin{array}{l}42 \cdot 0 \\
37 \cdot 7\end{array}$ & $\begin{array}{l}38 \cdot 6 \\
34 \cdot 6\end{array}$ & $\begin{array}{l}37 \cdot 9 \\
34 \cdot 3\end{array}$ \\
\hline $\begin{array}{l}5 \text { a.m. to } \\
11 \text { a.m. }\end{array}$ & $\begin{array}{l}\text { Primigravidae } \\
\text { Multigravidae }\end{array}$ & $\begin{array}{l}21 \cdot 0 \\
24 \cdot 9\end{array}$ & $\begin{array}{l}21 \cdot 8 \\
22 \cdot 5\end{array}$ & $\begin{array}{l}23 \cdot 0 \\
24 \cdot 9\end{array}$ & $\begin{array}{l}19 \cdot 9 \\
20 \cdot 2\end{array}$ \\
\hline $\begin{array}{l}11 \text { a.m. to } \\
5 \text { p.m. }\end{array}$ & $\begin{array}{l}\text { Primigravidae } \\
\text { Multigravidae }\end{array}$ & $\begin{array}{l}13 \cdot 2 \\
17 \cdot 4\end{array}$ & $\begin{array}{l}15 \cdot 5 \\
17 \cdot 2\end{array}$ & $\begin{array}{l}16 \cdot 7 \\
17 \cdot 7\end{array}$ & $\begin{array}{l}18 \cdot 4 \\
24 \cdot 2\end{array}$ \\
\hline $\begin{array}{l}5 \text { p.m. to } \\
11 \text { p.m. }\end{array}$ & $\begin{array}{l}\text { Primigravidae } \\
\text { Multigravidae }\end{array}$ & $\begin{array}{l}17 \cdot 7 \\
21 \cdot 3\end{array}$ & $\begin{array}{l}20 \cdot 7 \\
22 \cdot 6\end{array}$ & $\begin{array}{l}21 \cdot 7 \\
22 \cdot 8\end{array}$ & $\begin{array}{l}23 \cdot 8 \\
21 \cdot 3\end{array}$ \\
\hline
\end{tabular}

to 5 p.m., the differences between primigravidae and others are quite consistent, the former showing higher percentages in the maximum period and lower in the minimum. The shapes of the distributions are so much steeper in primigravidae, that in every case but one they also show lower percentages in the remaining 6 -hour periods.

Of the minor periodicities mentioned earlier, clumping at even numbers is shown only by the domiciliary multigravidae. There are indications of a 4-hourly period throughout the domiciliary births and among the institutional primigravidae. To show parity differences free from minor periodicities and irregularities, the four percentages for

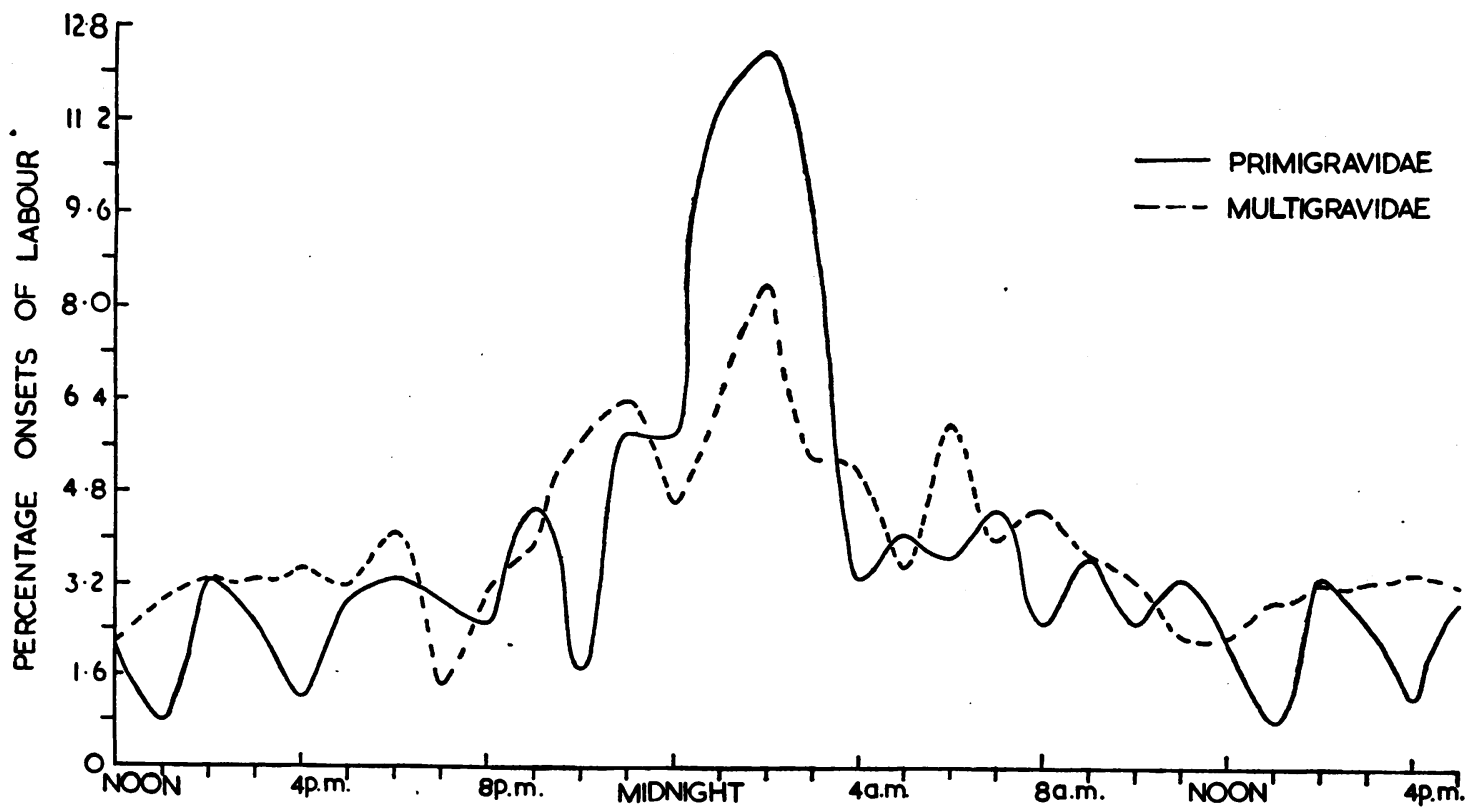

Fig. 2.-Percentage distribution of times of domiciliary onsets of labour in the month of August by parity. 


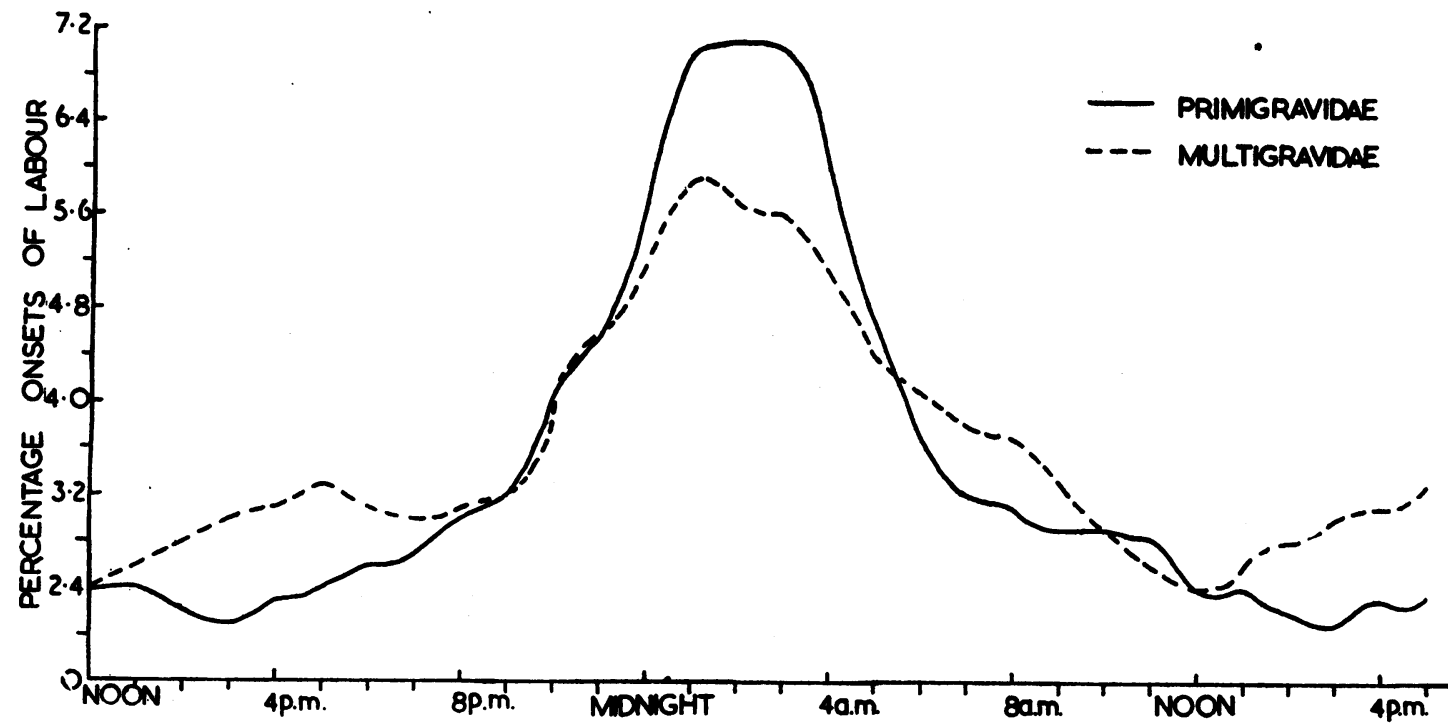

Fig. 3.-Percentage distribution of times of onset of labour by parity. 4-hour moving averages.

each parity sub-class were averaged and a four-hour moving average computed (Fig. 3). The graph shows the greater steepness of the primigravidae distribution and also indicates that the late day rise in times of onset starts earlier in multigravidae, so that there is an excess between 2 p.m. and 6 p.m.

(c) Domiciliary and Institutional Births.-Since the selection of eases excludes most of those with manifest medical indications for hospitalization, and since nearly all labours would start at home, there would seem to be no reason to expect any difference in times of onset between domiciliary and hospital births when parity is controlled. Nevertheless, as Table III shows, the domiciliary distributions are consistently steeper, though the difference is not so great as that between primigravidae and multigravidae. A higher proportion of first births are hospitalized so that when all parites are taken together the two effects noted tend to cancel each other out. The lower half of Table III shows domiciliary and institutional differences without distinction of parity. In the early part of the year, the domiciliary distributions are the steeper; in the latter part the reverse is the case. While the number of hospital beds remains the same throughout the year; the number of births is at a maximum in the early part of the year and least in November and December. This suggests a higher proportion of primigravidae delivered at home in the early part of the year, as was found to be the case when August was compared with November. The domiciliary and institutional figures of the latter part of Table III are thus consistent with previous results. For comparison with the previous section, Fig. 4 (opposite) shows unsmoothed percentage $\frac{D}{O}$ distributions for primigravidae in August, and Fig. $5 \cong$ (opposite) 4-hour moving averages for domiciliary $\vec{\varphi}$ and institutional primigravidae computed as beforg $\bar{\omega}$

(d) The Seasons.-Although elucidation of the possible effects of variation with reference to. intensity and amount of light, as also to the relative long wave-length content, was a major pre-occupation of the author's method of sub-dividing the TABLE III
PERCENTAGE DISTRIBUTION-TIMES OF ONSET-6-HOUR.
PERIODS

Domiciliary v. Institutional

\begin{tabular}{|c|c|c|c|c|c|c|}
\hline Parity & Month & $\begin{array}{l}\text { Type } \\
\text { of } \\
\text { Case }\end{array}$ & $\begin{array}{c}11 \text { p.m. } \\
\text { to } \\
5 \text { a.m. } \\
\text { Per } \\
\text { cent. }\end{array}$ & $\begin{array}{c}5 \text { a.m. } \\
\text { to } \\
11 \text { a.m. } \\
\text { Per } \\
\text { cent. }\end{array}$ & $\begin{array}{c}11 \text { a.m. } \\
\text { to } \\
5 \text { p.m. } \\
\text { Per } \\
\text { cent. }\end{array}$ & $\begin{array}{c}5 \text { p.m. } \\
\text { to } \\
11 \text { p.m. } \\
\text { Per } \\
\text { cent. }\end{array}$ \\
\hline \multirow{2}{*}{$\begin{array}{l}\text { Primi- } \\
\text { gravidae }\end{array}$} & August & $\begin{array}{c}\text { Domiciliary } \\
\text { Institutional }\end{array}$ & $\begin{array}{l}48 \cdot 1 \\
38 \cdot 6\end{array}$ & $\begin{array}{l}21 \cdot 0 \\
23 \cdot 0\end{array}$ & $\begin{array}{l}13 \cdot 2 \\
16 \cdot 7\end{array}$ & $\begin{array}{l}17 \cdot 7 \\
21 \cdot 7\end{array}$ \\
\hline & Nọvember & $\begin{array}{c}\text { Domiciliary } \\
\text { Institutional }\end{array}$ & $\begin{array}{l}42.0 \\
37.9\end{array}$ & $\begin{array}{l}21.8 \\
19.9\end{array}$ & $\begin{array}{l}15 \cdot 5 \\
18 \cdot 4\end{array}$ & $\begin{array}{l}20 \cdot 7 \\
23 \cdot 8\end{array}$ \\
\hline \multirow{2}{*}{$\begin{array}{l}\text { Multi- } \\
\text { gravidae }\end{array}$} & August & $\begin{array}{l}\text { Domiciliary } \\
\text { Institutional }\end{array}$ & $\begin{array}{l}36 \cdot 4 \\
34 \cdot 6\end{array}$ & $\begin{array}{l}24 \cdot 9 \\
24 \cdot 9\end{array}$ & $\begin{array}{l}17 \cdot 4 \\
17 \cdot 7\end{array}$ & $\begin{array}{l}21 \cdot 3 \\
22 \cdot 8\end{array}$ \\
\hline & $\overline{\text { November }}$ & $\begin{array}{l}\text { Domiciliary } \\
\text { Institutional }\end{array}$ & $\begin{array}{l}37 \cdot 7 \\
34 \cdot 3\end{array}$ & $22 \cdot 5$ & $\begin{array}{l}17 \cdot 2 \\
24 \cdot 2\end{array}$ & $22 \cdot 6$ \\
\hline \multirow{4}{*}{$\begin{array}{l}\text { All } \\
\text { Parities }\end{array}$} & March & $\begin{array}{l}\text { Domiciliary } \\
\text { Institutional }\end{array}$ & $\begin{array}{l}36 \cdot 2 \\
36 \cdot 1\end{array}$ & $\begin{array}{l}25 \cdot 3 \\
18 \cdot 2\end{array}$ & $\begin{array}{l}15 \cdot 8 \\
20 \cdot 3\end{array}$ & $\begin{array}{l}22 \cdot 7 \\
25 \cdot 4\end{array}$ \\
\hline & June & $\begin{array}{l}\text { Domiciliary } \\
\text { Institutional }\end{array}$ & $\begin{array}{l}38 \cdot 7 \\
37 \cdot 2\end{array}$ & $\begin{array}{l}21 \cdot 7 \\
21 \cdot 4\end{array}$ & $\begin{array}{l}17 \cdot 0 \\
18 \cdot 2\end{array}$ & $\begin{array}{l}22 \cdot 6 \\
23 \cdot 2\end{array}$ \\
\hline & September & $\begin{array}{l}\text { Domiciliary } \\
\text { Institutional }\end{array}$ & $\begin{array}{l}34 \cdot 7 \\
35 \cdot 5\end{array}$ & $\begin{array}{l}23 \cdot 5 \\
20 \cdot 7\end{array}$ & $\begin{array}{l}18 \cdot 9 \\
18 \cdot 6\end{array}$ & $22 \cdot 9$ \\
\hline & December & $\begin{array}{l}\text { Domiciliary } \\
\text { Institutional }\end{array}$ & $\begin{array}{l}34 \cdot 3 \\
36 \cdot 7\end{array}$ & $\begin{array}{l}24 \cdot 5 \\
22 \cdot 7\end{array}$ & $\begin{array}{l}19 \cdot 1 \\
16 \cdot 2\end{array}$ & $\begin{array}{l}22 \cdot 1 \\
24 \cdot 4\end{array}$ \\
\hline
\end{tabular}




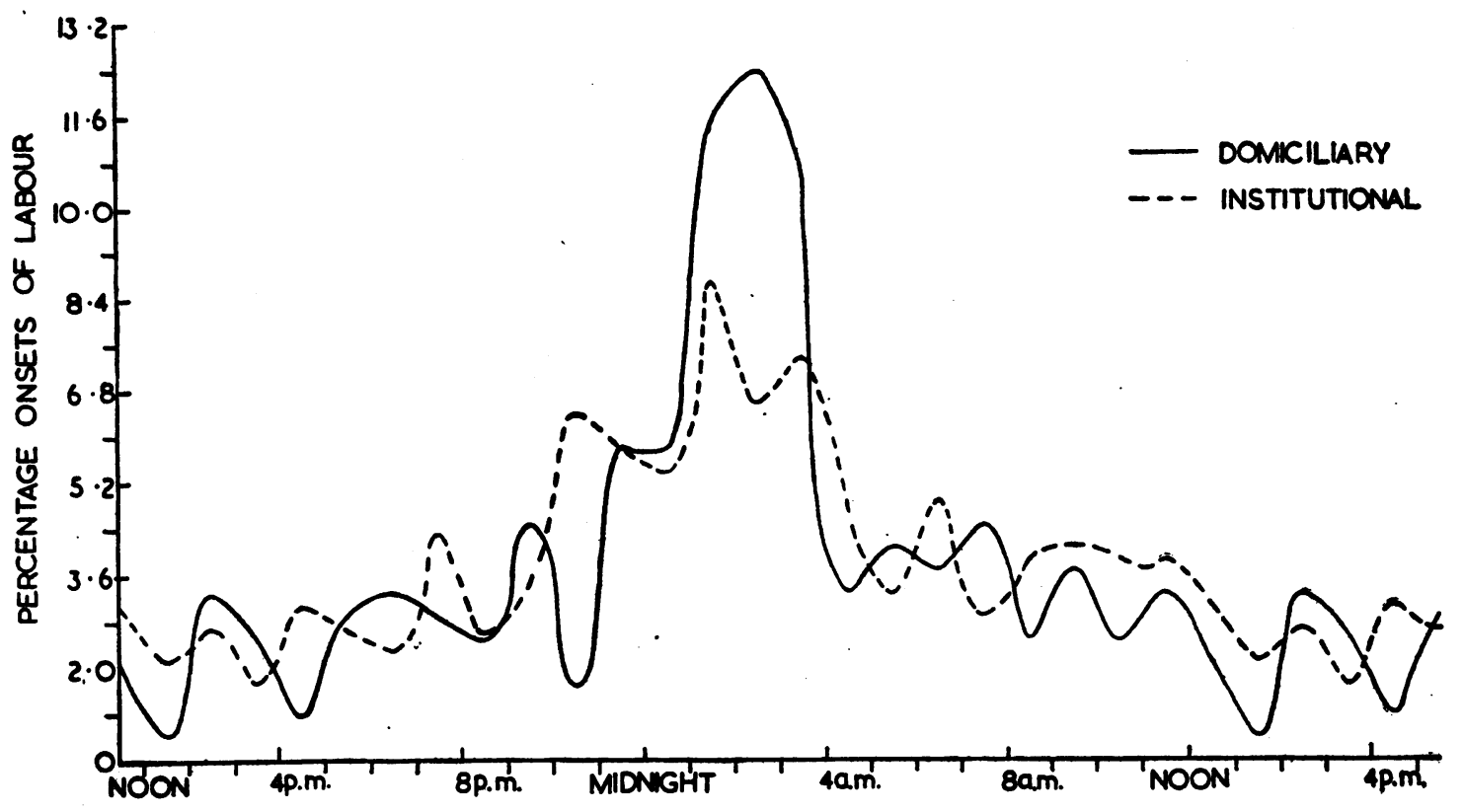

Fig. 4.-Percentage distribution of times of onset of labour in primigravidae. Domiciliary and institutional onsets in the month of August, unsmoothed.

data, the outcome has been to show that any maximum about 2 a.m. is clearly a response to a seasonal effect is small compared with effects socially determined daily rhythm largely indeassociated with parity and place of delivery. The pendent of seasonal influences. For the reason daily curve with a minimum about noon and a stated above, we should be able to show a shift of

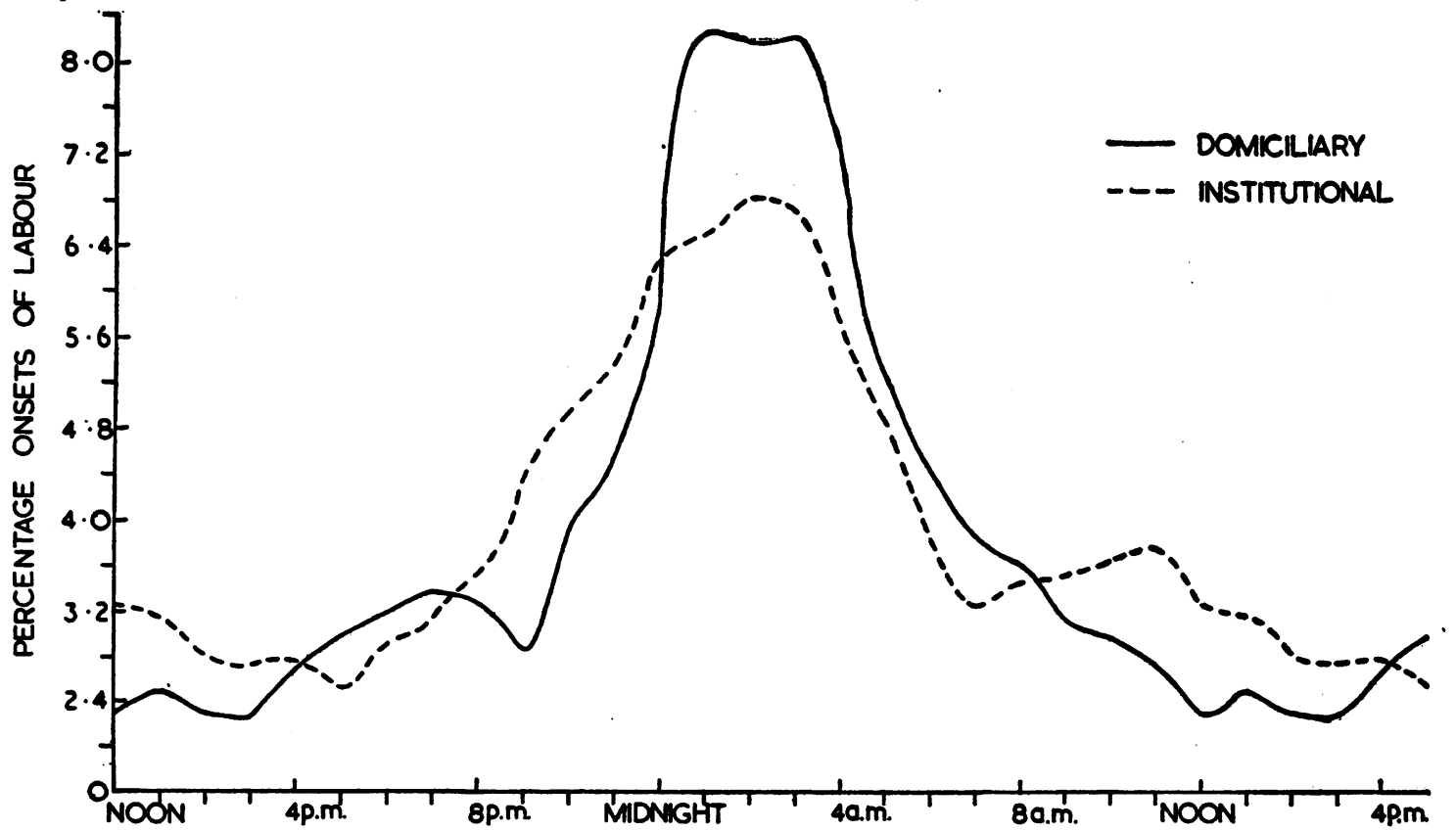

FIo. 5.-Percentage distribution of times of onset of labour in primigravidae. Domiciliary and institutional onsets in the month of August, 4-hour moving averages. 
nearly one hour between the daylight-saving months June, August, September, and the remainder, if the diurnal rhythm of onset time had its basis in the neurohumoral mechanism of pituitary activation by light. There is no trace of any such shift.

The figures for 6-hourly periods already given in Tables II and III show that for domiciliary cases the distribution for August is somewhat steeper than that for November. Table IV, covering four seasonal periods, suggests that the summer months tend to show a sharper peak than the winter months.

TABLE IV

PERCENTAGE DISTRIBUTION-TIMES OF ONSET-

\begin{tabular}{|c|c|c|c|c|c|}
\hline $\begin{array}{l}\text { Type of } \\
\text { Case }\end{array}$ & Season & $\begin{array}{c}11 \text { p.m. } \\
\text { to } \\
5 \text { a.m. } \\
\text { Percent. }\end{array}$ & $\begin{array}{c}5 \text { a.m. } \\
\text { to } \\
11 \text { a.m. } \\
\text { Percent. }\end{array}$ & $\begin{array}{c}11 \text { a.m. } \\
\text { to } \\
5 \text { p.m. } \\
\text { Pet cent. }\end{array}$ & $\begin{array}{l}5 \text { p.m. } \\
\text { to } \\
11 \text { p.m. } \\
\text { Per cent. }\end{array}$ \\
\hline Domiciliary & $\begin{array}{l}\text { June } \\
\text { Aug.-Sept. } \\
\text { Nov.-Dec. } \\
\text { March }\end{array}$ & $\begin{array}{l}38 \cdot 7 \\
36 \cdot 8 \\
36 \cdot 6 \\
36 \cdot 2\end{array}$ & $\begin{array}{l}21 \cdot 7 \\
23.9 \\
23.3 \\
25 \cdot 3\end{array}$ & $\begin{array}{l}17.0 \\
177.8 \\
17.9 \\
15.8\end{array}$ & $\begin{array}{l}22 \cdot 6 \\
21 \cdot 5 \\
22 \cdot 2 \\
22 \cdot 7\end{array}$ \\
\hline Institutional & $\begin{array}{l}\text { June } \\
\text { Aug.-Sept. } \\
\text { Nov--Dec. } \\
\text { March }\end{array}$ & $\begin{array}{l}37 \cdot 2 \\
36 \cdot 5 \\
36 \cdot 3 \\
36 \cdot 1\end{array}$ & $\begin{array}{l}21 \cdot 4 \\
22 \cdot 5 \\
21 \cdot 2 \\
18 \cdot 2\end{array}$ & $\begin{array}{l}18 \cdot 2 \\
17 \cdot 1 \\
19 \cdot 3 \\
20 \cdot 3\end{array}$ & $\begin{array}{l}23 \cdot 2 \\
23 \cdot 9 \\
23 \cdot 2 \\
25 \cdot 4\end{array}$ \\
\hline
\end{tabular}

This point is further illustrated by Fig. 6, which compares the unsmoothed distributions for domiciliary cases in June and March, and by Fig. 7 (opposite), which gives 4-hourly averages for the four seasons.
The summer-winter difference may be possibly a response to red light bringing about onset of labour somewhat earlier in the day and thus flattening the curve. The absence of clear-cut seasonal differences makes any such suggestion necessarily speculative particularly in the artificial conditions of life in a large smoke-polluted city. In the light of the present inquiry, we suggest that an investigation $\bar{\partial}$ of a sufficient number of rural domiciliary births, classified by parity, might prove of biological interest.

(e) Rejected Cases and Stillbirths.-As described earlier, 3,794 cases were omitted from analysis because of some features likely to affect the course. of labour more or less adversely. Though a very $\overrightarrow{\vec{\omega}}$ heterogeneous assemblage, the picture presented by these cases, together with 386 stillbirths, may $\overparen{D}$ prove suggestive. Fig. 8 (opposite) shows the un-? smoothed distributions of the rejected cases compared iv with those analysed above. The distribution as well as being flatter, is markedly shifted to the left. The peak is now at 10 p.m. and the minimum at 8 a.m. The shape of the curve is obviously quite different from any encountered previously.

Fig. 9 (overleaf) gives 4-hour moving averages for the rejected cases, sub-divided into domiciliary and $\mathscr{G}$ institutional, and for the stillbirths. The stillbiri distribution has shifted still further to the lef, and there is a suggestion of bimodality, in the

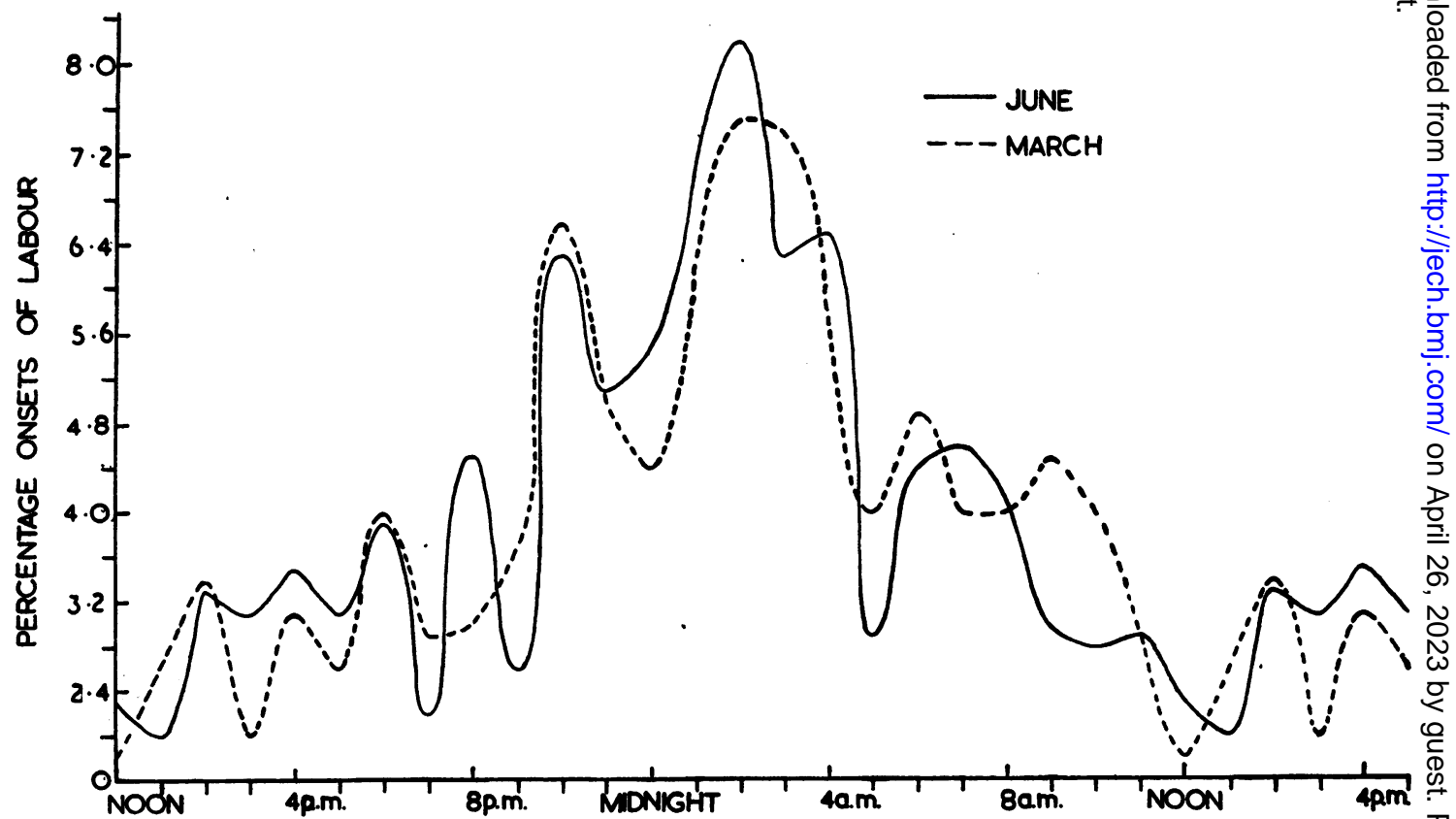

F1G. 6.-Percentage distribution of times of onset of labour. Domiciliary onsets for the months of March and June, unsmoothed. 


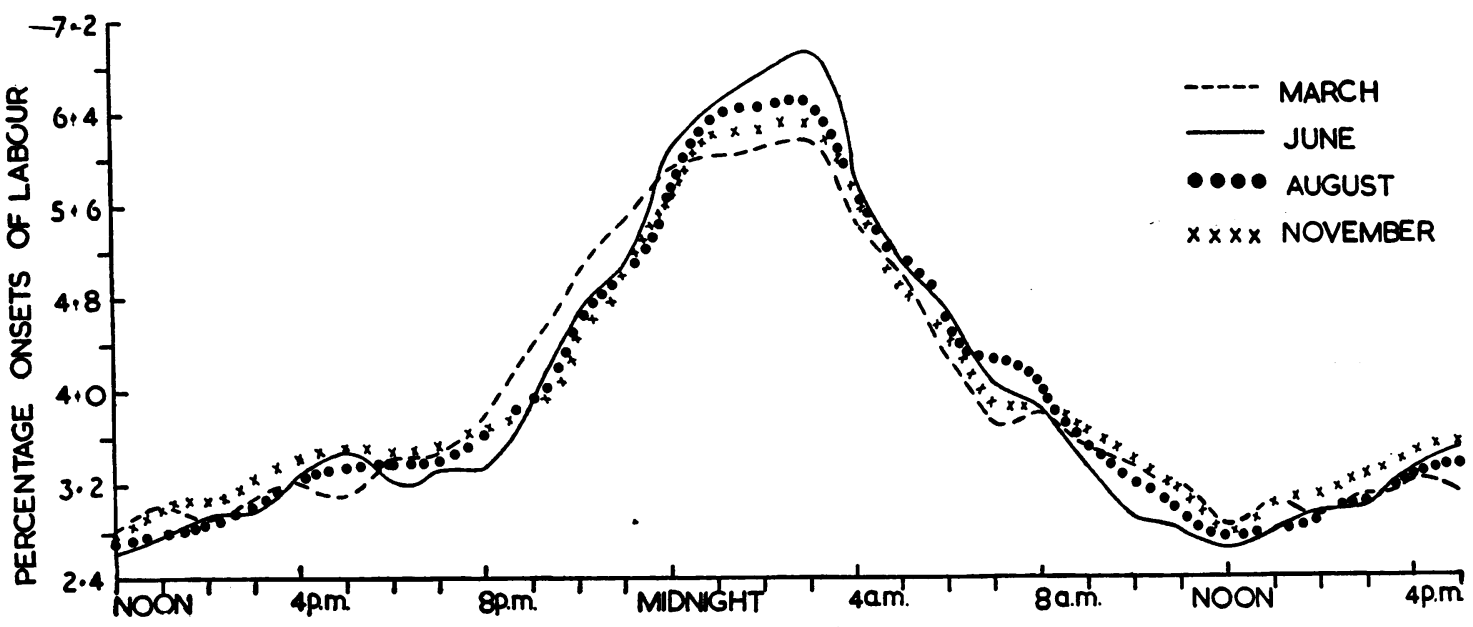

FIG. 7.-Percentage distribution of times of domiciliary onsets of labour in March, June, August, and November.

superimposed on the maximum period found previously round 2 a.m., there is a high frequency group of onsets between 5 p.m. and 11 p.m. The tendency for onset to occur earlier with what may possibly be increasing severity of pathology is shown in Table $\mathrm{V}$, which gives the percentages in two of the 6-hour periods used previously.

\section{(4) TIME OF Delivery}

(a) All Selected Cases.-The distribution of durations of labour in Birmingham over the relevant period is known. It is extremely skew with the mode
TABLE V

PERCENTAGE DISTRIBUTION-TIMES OF ONSET REJECTED CASES OR STILLBIRTHS-6-HOUR PERIODS

\begin{tabular}{|c|c|c|c|}
\hline Type of Case & & $\begin{array}{l}5 \text { p.m. to } 11 \text { p.m. } \\
\text { Per cent. }\end{array}$ & $\begin{array}{l}11 \text { p.m. to } 5 \text { a.m. } \\
\text { Per cent. }\end{array}$ \\
\hline $\begin{array}{l}\text { Selected } \\
\text { Domiciliary } \\
\text { Institutional Rejected } \\
\text { Stillbirths }\end{array}$ & $\begin{array}{l}\because \\
\because \\
\because\end{array}$ & $\begin{array}{l}22 \cdot 9 \\
25 \cdot 0 \\
27 \cdot 2 \\
30 \cdot 5\end{array}$ & $\begin{array}{l}36 \cdot 7 \\
33 \cdot 8 \\
30 \cdot 4 \\
29 \cdot 7\end{array}$ \\
\hline
\end{tabular}

for primigravidae at about 8 hours, and for multigravidae at about 4 hours. In the present inquiry, the 24-hour cycle is being investigated, so that

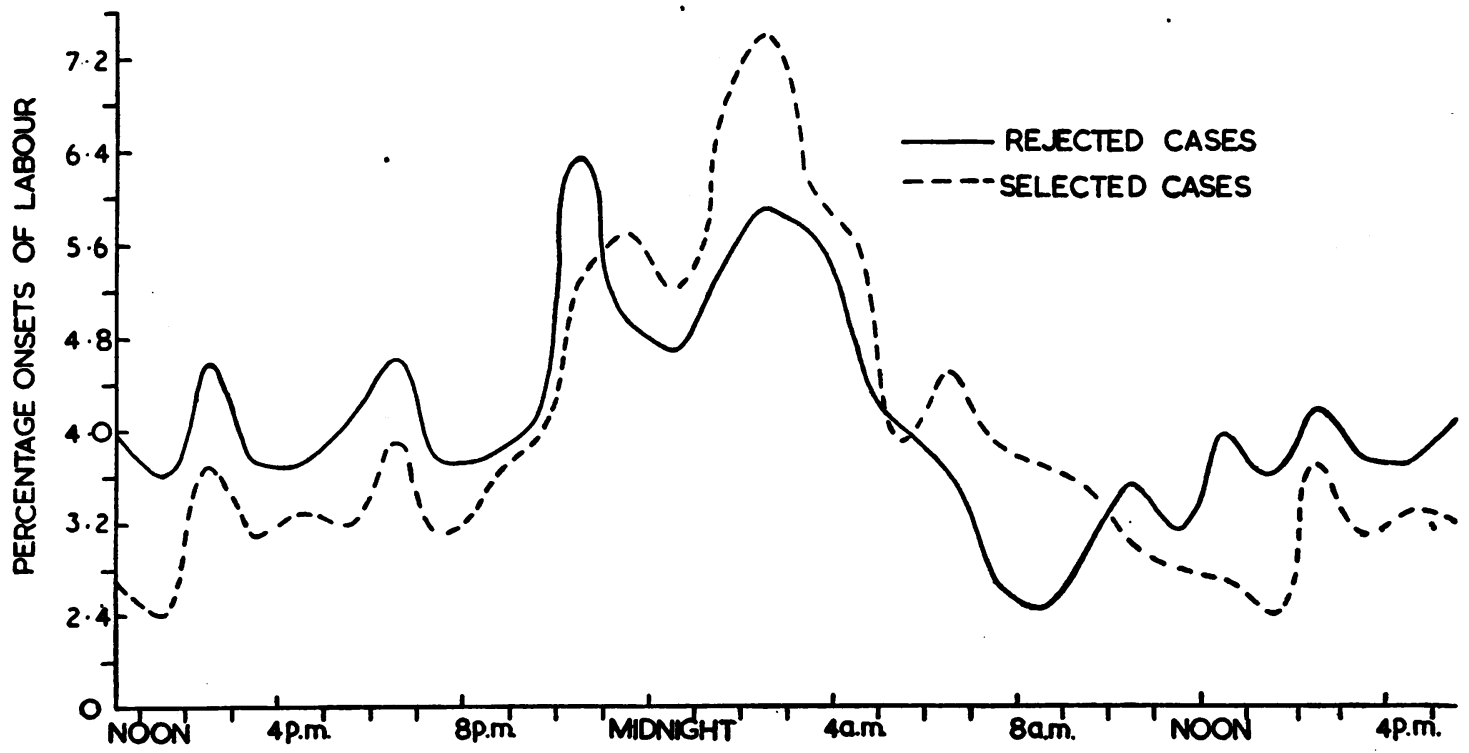

FIG. 8.-Percentage distribution of times of onset of labour in selected and rejected births. Unsmoothed. 


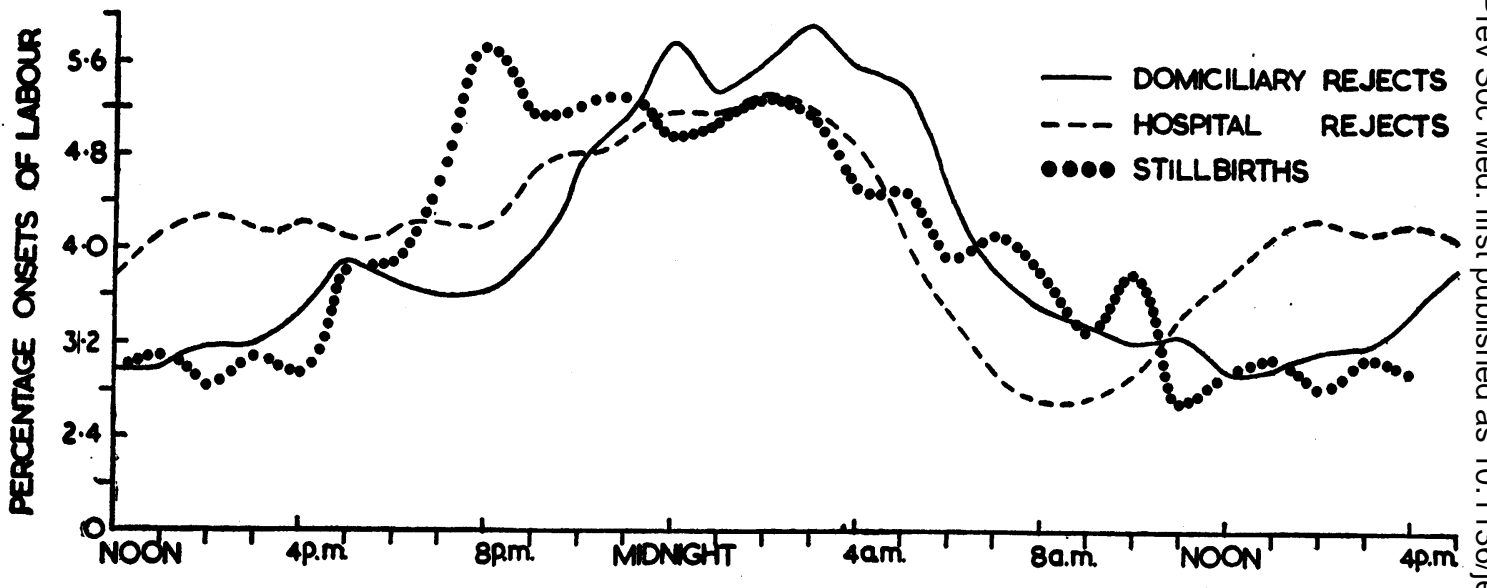

Fio. 9.-Percentage distribution of times of onset of labour in rejected hospital births, rejected domiciliary births, and stillbirths. $\stackrel{\curvearrowright}{\supset}$ 4-hour moving averages.

durations of 1 hour and 25 hours, etc., are equivalent. With this in mind, we might suppose that the distribution of delivery times could be predicted from that of times of onset. We should expect to see a much flatter curve with peaks, if any, at about 6 a.m. and 10 a.m., since the modal time of onset was almost invariably at 2 a.m. The absence of clumping, due to more accurate recording of delivery times, would also lead to greater scatter.

The actual distribution found for the selected cases whose times of onset are given in Fig. 1 and Table I is shown in Table VI (below) and Fig. 10 (opposite). Appendix Table B (p. 59) gives the raw data. There are a few differences in total numbers, due to times of delivery being available without times of onset, and very occasionally, the reverse situation. The numbers involved are not large enough to affect the comparability of the two sets of data.

TABLE VI

PERCENTAGE DELIVERIES BY TIME OF DAY (Selected Cases)

\begin{tabular}{c|c|c|c}
\hline Time of Day & Per cent. & Time of Day & Per cent. \\
\hline 12 Midnight & 4.1 & 12 Noon & 3.8 \\
1 a.m. & 4.3 & 1 p.m. & 3.8 \\
2 a.m. & 5.0 & 2 p.m. & 3.6 \\
3 a.m. & 5.5 & 3 p.m. & 3.6 \\
4 a.m. & 5.2 & 4 p.m. & 3.7 \\
5 a.m. & 4.7 & 5 p.m. & 3.7 \\
6 a.m. & 4.9 & 6 p.m. & 3.7 \\
7 a.m. & 4.8 & 7 p.m. & 3.6 \\
8 a.m. & 4.4 & 8 p.m. & 3.4 \\
9 a.m. & 3.9 & 9 p.m. & 4.0 \\
10 a.m. & 3.6 & 10 p.m. & 3.8 \\
11 a.m. & 4.0 & 11 p.m. & 4.9 \\
\hline
\end{tabular}

As was expected, the curve of delivery times is very much flatter than that of times of onset, and there is no trace of clumping at even numbers. The 12-hour period containing the most deliveries is at night between 9 p.m. and 9 a.m., with 55.6 per cent. $\frac{\vec{\omega}}{\omega}$ of all deliveries. Thirty per cent. occur in the 6-hour 0 period, 2 a.m. to 8 a.m., instead of the expected 25 per cent.

When, however, we compare the peak period with the peak times of onset, it is seen to be different $\vec{\theta}$ from expectation. Both the unsmoothed curve and of the 4-hour moving average show a maximum on one hour later than the maximum time of onse In describing the expected times of delivery, the assumption was made that there was no reason to

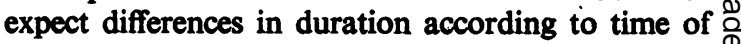

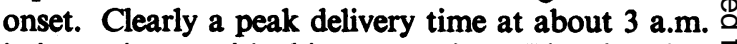
is inconsistent with this assumption. The situation $\overrightarrow{\overrightarrow{0}}$ can be seen more clearly when we examine primi- 3 gravidae and multigravidae separately. To verify that deductions from the known parity sub-classes are applicable to the whole group, Fig. 10.also shows the percentage distribution of all cases with known $\stackrel{9}{?}$ parities. In so far as the maxima are concerned, the distribution of the smaller class corresponds very closely to that of the whole.

(b) Parity.-Figs 11 and 12 (opposite) show distributions of delivery times for primigravidae and multigravidae respectively. Owing to the much greater spread of durations in primigravidae, the curve of delivery times is, as one would expect, $O$ much flatter, and the longer durations bring more $N$ deliveries into the day-time. The 12-hour period $\mathrm{N}_{\mathrm{W}}$ with most first deliveries is between 3 a.m. and 3 p.m. with 53.2 per cent. of all deliveries. Twentyeight per cent. occur between 6 a.m. and 12 noon. In fact, for practical purposes, one might say that $\stackrel{9}{?}$ first deliveries are evenly distributed throughout $T$ the 24 hours. 


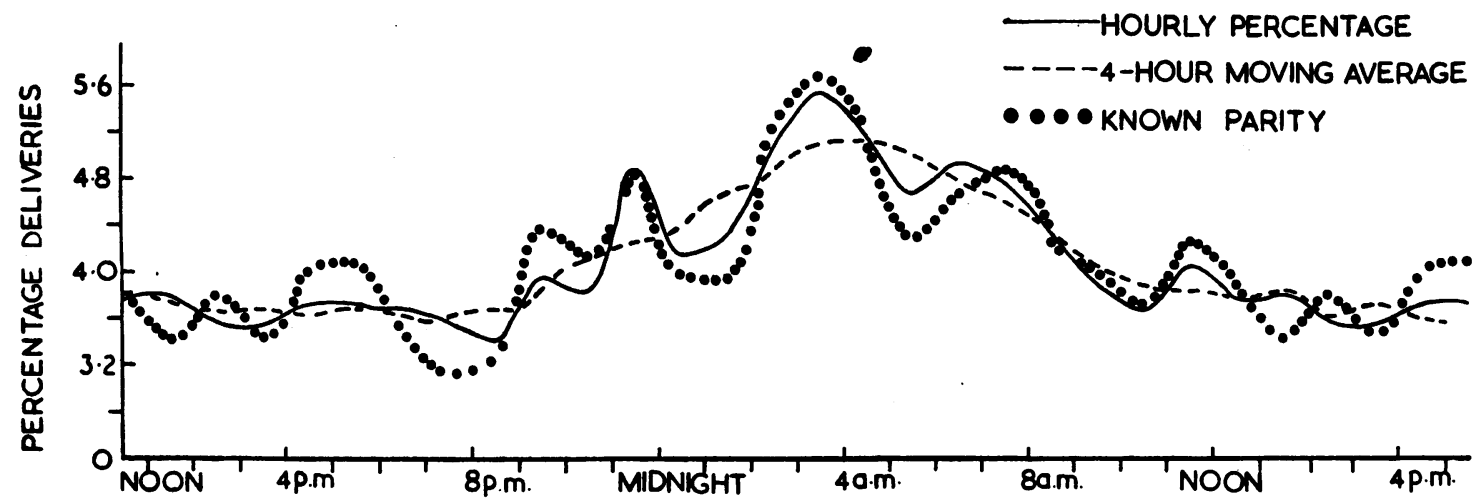

Fio. 10.-Percentage distribution of times of delivery in all selected births.

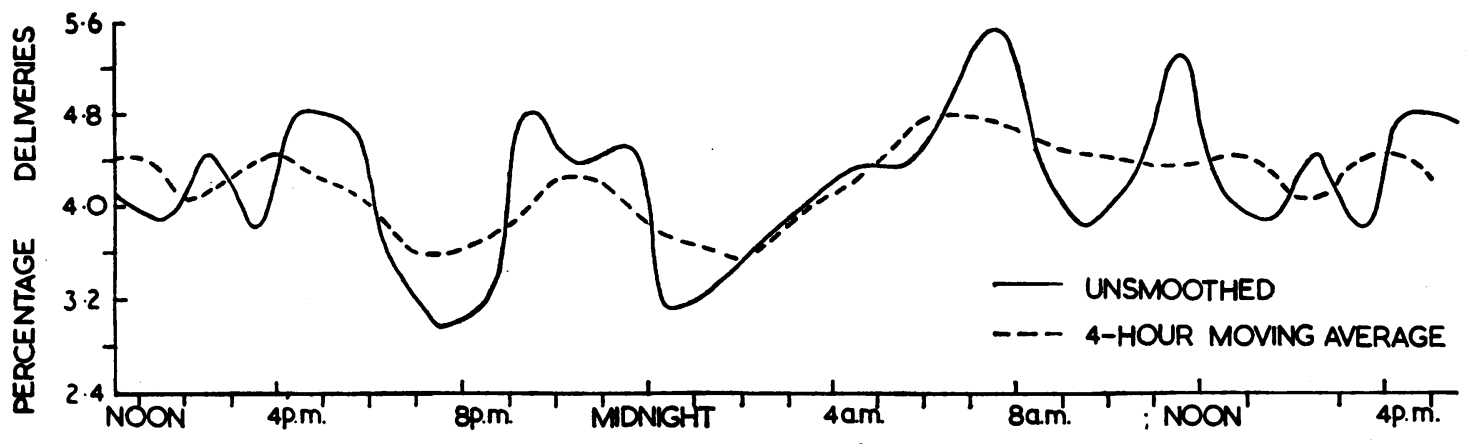

Fro. 11.-Percentage distribution of times of delivery of primigravidae, unsmoothed and 4-hour moving averages.

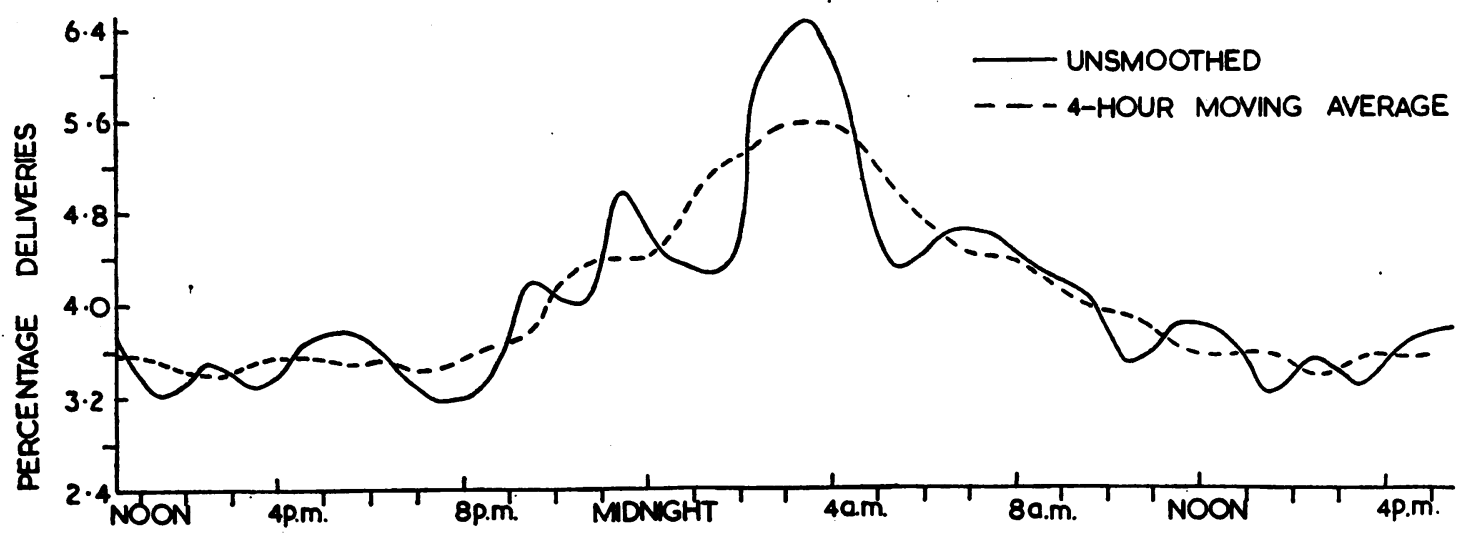

Fio. 12.-Percentage distribution of times of delivery of multigravidae, unsmoothed and 4-hour moving averages.

Multigravidae show a more definite maximum. The 12-hour period with the most deliveries is between 9 p.m. and 9 a.m., which includes 57.5 per cent. of all deliveries. In the 6-hour period 2 a.m. to 8 a.m. are found 31.4 per cent. of the deliveries. Both distributions show the discrepancy referred to previously, in that the hour of maximum occurrence is some 3 hours earlier than would be expected from the times of onset.
The relationship between time of onset and duration of labour is a complex one. What seems to determine the form of the delivery time curve is the modal duration for each time of onset, but, owing to the small numbers at single hours, the mode in this context can be extended to mean the 3-hour period with the largest number of durations. If all other durations are disregarded, and delivery times calculated from these durations alone, a 
distribution can be obtained which is very close to the actual one. The 3-hourly modes for primigravidae and multigravidae are given in Table VII.

TABLE VII

MODAL DURATIONS OF LABOUR FOR DIFFERENT TIMES OF ONSET

(25 hours $=1$ hour, etc.)

\begin{tabular}{|c|c|c|c|}
\hline \multicolumn{2}{|c|}{ Primigravidae } & \multicolumn{2}{|c|}{ Multigravidae } \\
\hline $\begin{array}{l}\text { Modal Duration } \\
\text { (hrs) }\end{array}$ & Time of Onset & $\underset{\text { (hrs) }}{\text { Modal Duration }}$ & Time of Onset \\
\hline $5-7$ & 12 Midnight & $1-3$ & 5 a.m. \\
\hline \multirow[t]{2}{*}{$6-8$} & \multirow{2}{*}{$\begin{array}{r}1 \text { a.m. } \\
3 \text { a.m. } \\
4 \text { a.m. } \\
2 \text { p.m. } \\
8 \text { p.m. } \\
10 \text { p.m. }\end{array}$} & $2-4$ & 1 a.m. \\
\hline & & $3-5$ & $\begin{array}{c}12 \text { Midnight } \\
4 \text { a.m. } \\
8 \text { p.m. } \\
11 \text { p.m. }\end{array}$ \\
\hline $7-9$ & $\begin{array}{r}2 \text { a.m. } \\
6 \text { p.m. } \\
11 \text { p.m. }\end{array}$ & \multirow[t]{3}{*}{$4-6$} & \multirow{3}{*}{$\begin{array}{r}2 \text { a.m. } \\
3 \text { a.m. } \\
6 \text { a.m. } \\
7 \text { a.m. } \\
9 \text { a.m. } \\
11 \text { a.m. } \\
9 \text { p.m. } \\
10 \text { p.m. }\end{array}$} \\
\hline $8-10$ & $\begin{array}{l}8 \text { a.m. } \\
9 \text { a.m. }\end{array}$ & & \\
\hline \multirow[t]{3}{*}{$9-11$} & \multirow{3}{*}{$\begin{aligned} 5 & \text { a.m. } \\
11 & \text { a.m. } \\
1 & \text { p.m. } \\
5 & \text { p.m. } \\
7 & \text { p.m. }\end{aligned}$} & & \\
\hline & & $5-7$ & $\begin{array}{l}5 \text { p.m. } \\
7 \text { p.m. }\end{array}$ \\
\hline & & \multirow{3}{*}{$6-8$} & \multirow{3}{*}{$\begin{array}{l}10 \text { a.m. } \\
12 \text { Noon } \\
2 \text { p.m. } \\
3 \text { p.m. } \\
4 \text { p.m. } \\
6 \text { p.m. }\end{array}$} \\
\hline $10-12$ & $\begin{array}{l}6 \text { a.m. } \\
7 \text { a.m. } \\
10 \text { a.m. }\end{array}$ & & \\
\hline \multirow[t]{2}{*}{$11-13$} & \multirow{2}{*}{$\begin{array}{l}12 \text { Noon } \\
1 \text { p.m. } \\
3 \text { p.m. }\end{array}$} & & \\
\hline & & 7-9 & 8 a.m. \\
\hline $12-14$ & 9 p.m. & \multirow[t]{2}{*}{$8-10$} & \multirow[t]{2}{*}{1 p.m. } \\
\hline 14-16 & 4 p.m. & & \\
\hline
\end{tabular}

To explain the distributions in detail would require a ponderous amount of arithmetic, but Table VII should suffice to indicate that the antedating of the major peaks for both primigravidae and multigravidae results from a piling-up of short durations from two directions. In labours starting at 11 p.m., midnight, and 1 a.m., the mode is reached early, but in labours starting at 4 a.m. to 7 p.m. it is reached late and both contribute to the maximum found.

The apparent differences in duration of labour according to time of onset have some general interest. So Figs 13 and 14 (opposite) compare frequencies of duration according to whether onset occurs during the night (defined as the 12-hour period $8 \mathrm{p} . \mathrm{m}$. to $8 \mathrm{a} . \mathrm{m}$.) or during the day. The difference is most clearly marked for multigravidae, but both parity groups show a greater frequency of short durations. This is confirmed by the mean duration of labour:

primigravidae: night, $15.9 \mathrm{hrs}$; day, $17 \cdot 2 \mathrm{hrs,}$ multigravidae: night, $9.6 \mathrm{hrs}$; day, $10.5 \mathrm{hrs}$.
The explanation suggests itself that when labour starts during sleep the first few contractions may not awake the subject and thus the duration may appear shorter. This would, however, hardly seem to account for the shorter durations starting at 10 and 11 p.m., and it might be that when the day's activities are over the uterus is more relaxed and a slight advantage gained in the course of labour.

Since the pattern of delivery times is so different for primigravidae and multigravidae, detailed study of domiciliary compared with institutional births would be fruitless with the relatively small numbers available after parities have been distinguished. It is also worth noting that the distributions of delivery times are more irregular than those of onset times, possibly because of the superimposition of widely varying duration times upon a comparatively simple pattern of onset times, so that the order manifest in the smallest groups of onset times is less easy to detect. We shall, therefore, after examining the rejected cases and stillbirths, present Tables of mainly administrative interest showing the delivery times of all births.

(c) Delivery Times for All Births.-Fig. 15 (opposite) shows 4-hour moving averages for rejected cases and stillbirths. As would be expected from the onset times, deliveries in both types are more evenlyo distributed throughout the 24 hours. For rejected cases, 52 per cent. of deliveries occur between 9 p.m and 9 a.m., and 28 per cent. between 11 p.m. and 5 a.m. This is but little in excess of a uniform hourly distribution. For stillbirths the maximum 12-hour period is from noon to midnight with 54 per cent. of deliveries; 30 per cent. occur between 1 p.m. and 7 p.m., but the number of cases is so small (386) that the afternoon peak may be of little significance.

For administrative purposes, the incidence of all deliveries irrespective of type is of interest. Table VIII (overleaf) gives frequencies of domiciliary and institutional births and of all births taken together. Live births comprise all recorded cases during stated parts of 1950 and 1951, as described in Section 2. The corresponding numbers of stillbirths were estimated from the distribution of all 1951 stillbirths found in that year.

(i) Taking all births together, the 12-hour period with the most deliveries is from $9 \mathrm{p}$ :m. to 9 a.m. ( 54.8 per cent.). The peak hour is 3 to 4 a.m., and 29 per cent. of deliveries occur in the 6-hour period 2 to 8 a.m.

(ii) The domiciliary distribution is somewhat steeper. For the same period, 55.5 per cent. of domiciliary deliveries occur at night compared with $54 \cdot 1$ per cent. of institutional deliveries. In the peak 6-hour period are found 30.3 per cent. domiciliary deliveries and 27.9 per cent. institutional. 


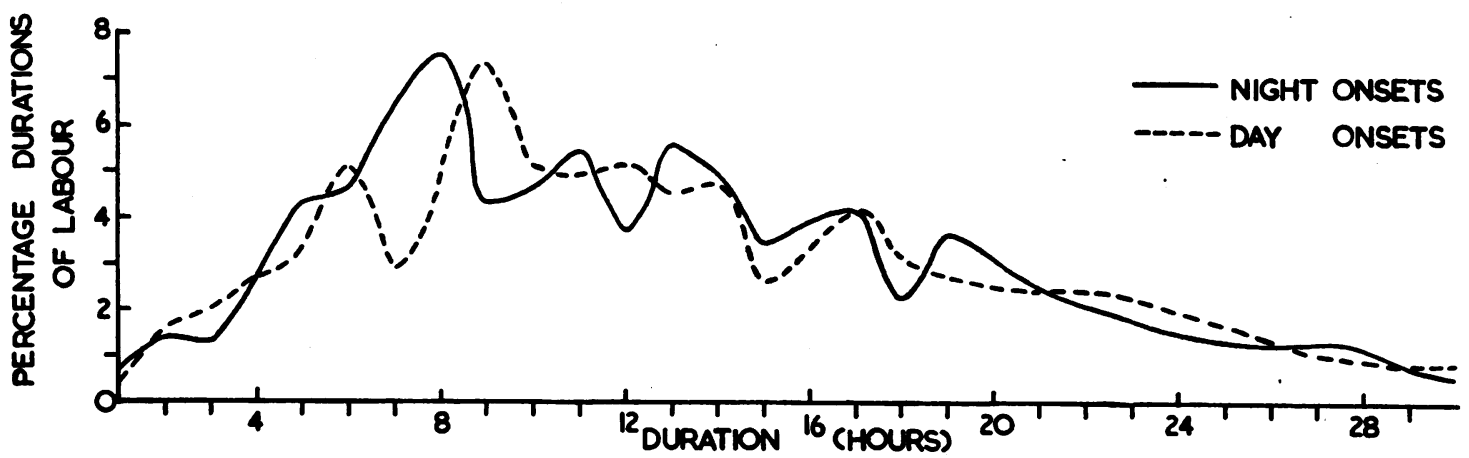

Fio. 13.-Percentage distribution of durations of labour by day and night onset in primigravidae.

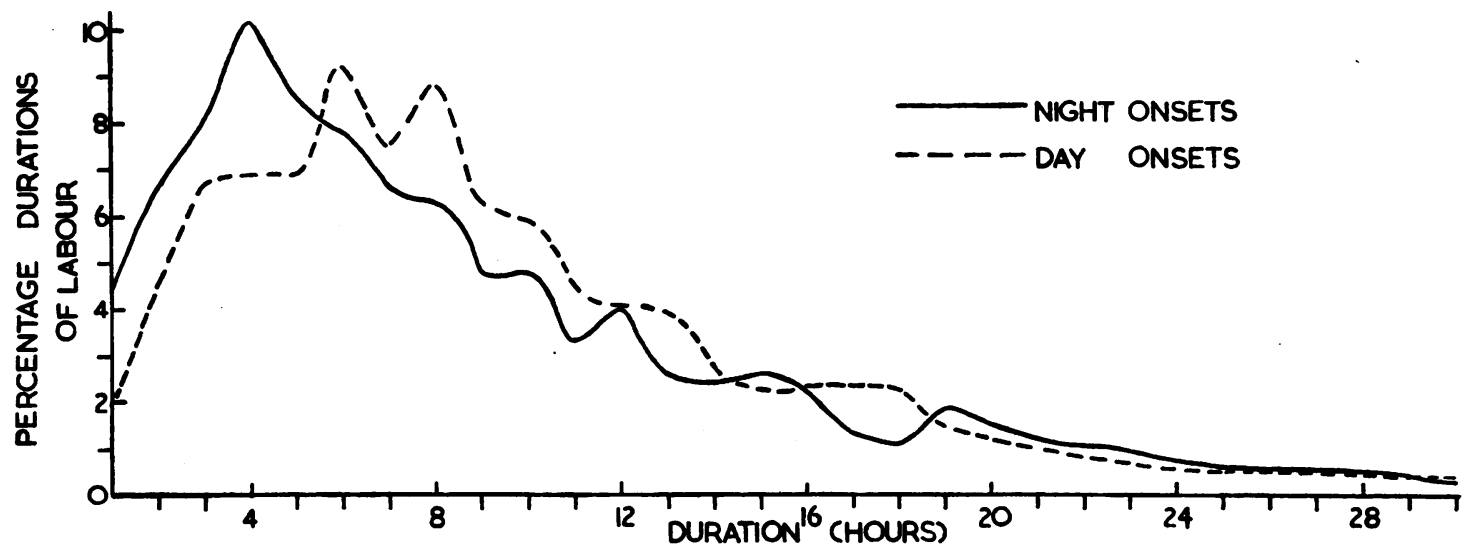

Fio. 14.-Percentage distribution of durations of labour by day and night onset in multigravidae.

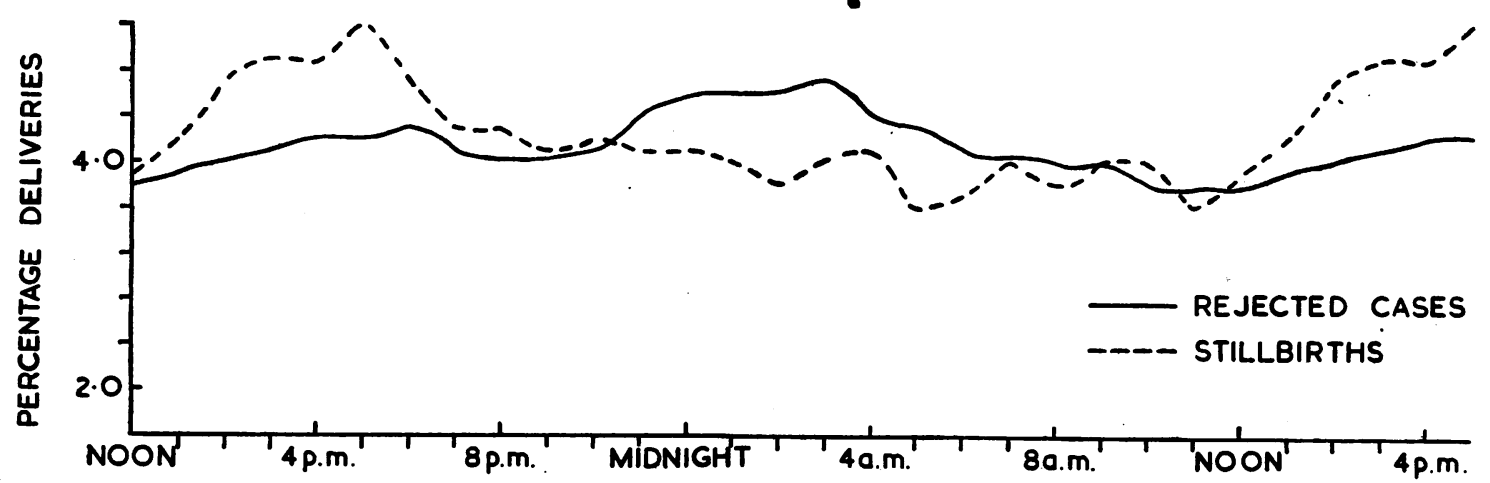

Fro. 15.-Percentage distribution of times of delivery in all rejected cases and stillbirths. 4-hour moving averages. 
(iii) The domiciliary deliveries are also later. The maximum 12-hour period is from 10 p.m. to 10 a.m., though the difference is trivial, and the peak hour is 4 to 5 a.m. On the other hand; the maximum 6-hour period for institutional births is from 11 p.m. to 5 a.m., with $28 \cdot 3$ per cent. of the deliveries.

TABLE VIII

ESTIMATED FREQUENCIES OF DELIVERY TIMES-ALL LIVE AND STILL BIRTHS, BIRMINGHAM, 1950, 1951

\begin{tabular}{|c|c|c|c|}
\hline Time of Delivery & $\begin{array}{c}\text { Domiciliary } \\
\text { Births } \\
\text { Per cent. }\end{array}$ & $\begin{array}{c}\text { Institutional } \\
\text { Births } \\
\text { Per cent. }\end{array}$ & $\begin{array}{l}\text { All Births } \\
\text { Per cent. }\end{array}$ \\
\hline $\begin{array}{l}12 \text { Midnight } \\
1 \text { a.m. } \\
2 \text { a.m. } \\
3 \text { a.m. } \\
4 \text { a.m. } \\
5 \text { a.m. } \\
6 \text { a.m. } \\
7 \text { a.m. } \\
8 \text { a.m. } \\
9 \text { a.m. } \\
10 \text { a.m. } \\
11 \text { a.m. }\end{array}$ & $\begin{array}{l}3 \cdot 8 \\
4 \cdot 4 \\
5 \cdot 2 \\
5 \cdot 3 \\
5 \cdot 4 \\
4 \cdot 6 \\
4 \cdot 9 \\
4 \cdot 9 \\
4 \cdot 6 \\
3 \cdot 7 \\
3 \cdot 7 \\
4 \cdot 0\end{array}$ & $\begin{array}{l}4 \cdot 6 \\
4 \cdot 4 \\
4 \cdot 6 \\
5 \cdot 3 \\
4 \cdot 7 \\
4 \cdot 4 \\
4 \cdot 4 \\
4 \cdot 4 \\
4 \cdot 2 \\
4 \cdot 0 \\
3 \cdot 6 \\
3 \cdot 9\end{array}$ & $\begin{array}{l}4 \cdot 2 \\
4 \cdot 4 \\
4.9 \\
5 \cdot 3 \\
5 \cdot 0 \\
4 \cdot 5 \\
4.7 \\
4.6 \\
4.4 \\
3.9 \\
3.7 \\
3 \cdot 9\end{array}$ \\
\hline $\begin{array}{l}12 \text { No.on } \\
1 \text { p.m. } \\
2 \text { p.m. } \\
3 \text { p.m. } \\
4 \text { p.m. } \\
5 \text { p.m. } \\
6 \text { p.m. } \\
7 \text { p.m. } \\
8 \text { p.m. } \\
9 \text { p.m. } \\
10 \text { p.m. } \\
11 \text { p.m. }\end{array}$ & $\begin{array}{l}3 \cdot 6 \\
3 \cdot 6 \\
3 \cdot 5 \\
3 \cdot 3 \\
3 \cdot 8 \\
4 \cdot 0 \\
3 \cdot 8 \\
3 \cdot 7 \\
3 \cdot 7 \\
3 \cdot 7 \\
3 \cdot 7 \\
5 \cdot 1\end{array}$ & $\begin{array}{l}4 \cdot 1 \\
4 \cdot 0 \\
3 \cdot 9 \\
4 \cdot 0 \\
4 \cdot 0 \\
3 \cdot 6 \\
3 \cdot 8 \\
3 \cdot 8 \\
3 \cdot 3 \\
4 \cdot 2 \\
4 \cdot 2 \\
4 \cdot 6\end{array}$ & $\begin{array}{l}3 \cdot 8 \\
3 \cdot 8 \\
3 \cdot 7 \\
3 \cdot 7 \\
3 \cdot 9 \\
3 \cdot 8 \\
3 \cdot 8 \\
3 \cdot 7 \\
3 \cdot 5 \\
4 \cdot 0 \\
4 \cdot 0 \\
4 \cdot 8\end{array}$ \\
\hline Total & $100 \cdot 0$ & $100 \cdot 0$ & $100 \cdot 0$ \\
\hline
\end{tabular}

The results of Table VIII can be compared with the two other sets of data previously mentioned for Lancashire and New York, the latter being available for 3-hourly periods only. It is not clear whether the Lancashire figures include stillbirths and the proportion of these is higher in the New York data, but the proportion of stillbirths is in any event too small to affect the broad picture. In general the Birmingham results agree fairly well with both New York and Lancashire, perhaps more closely with the latter. All three sources give a peak period between 3 and 6 a.m. The New York distribution shows the least difference between day and night, and the Lancashire figures the most, but in the latter case the maximum 12-hour period starts at 11 p.m.

The main point in which the Birmingham data differ from the other two is that both New York and Lancashire show a pronounced peak at about 10 a.m. This is found in New York in both live and still births, being particularly marked in the latter. One of the four sub-classes of Birmingham primigravidae show a pronounced peak at 10 a.m., but otherwise there is no trace of one. The primigravidae, as a whole, however, have a pronounced peak at 11 a.m. which probably corresponds to the Lancashire one (Fig. 11). This peak is visible in the graph of all selected cases (Fig. 10), though it has almost disappeared when all live and still births are taken together. The Lancashire and Birmingham patterns could be reconciled if there were a considerably higher proportion of first births in Lancashire. A high proportion of first births is indicative of low fertility, and the textile districts of Lancashire have long been known to be relatively very infertile (Charles and Moshinsky, 1938). The RegistrarGeneral's Annual Statistical Review for 1949 gives the ratio of adjusted birth rates in Birmingham and the Administrative County of Lancashire as $1.05: 0.97$. From the adjusted rates for the separate portions of Health District No. 17, it appears that the total adjusted rate for the district as a whole would be a little below that for the Administrative County (Lancashire, 1952). It seems highly probable therefore that the Lancashire data contain a high proportion of first births. Unfortunately the same explanation cannot be invoked in the case of New York. It is highly unlikely that the proportion of first births at that period could be higher than in Birmingham, 1950-51. However, the figures quoted by Bradford Hill are clearly only a small fraction of all the births in New York Stated in 10 years, so that speculation would be profitless in the absence of fuller information. In any event, the spectacular fall in maternal mortality during recent years would cast doubt on the statistical comparability of an inquiry into conditions affecting childbirth 30 years ago.

If the suggested interpretation of the LancashireBirmingham difference is correct, we can suppose that in the future falling fertility would lead to a more even distribution of deliveries as between day and night. On the other hand, improvement in the health of the pregnant mother would be likely to yield a steeper curve by reducing the incidence of pathological conditions and shortening the duration of labour. To some extent the two anticipations cancel one another out, but we can perhaps envisage a continuing clear distinction between the two halves of the day, the maximum 12-hour period tending to be from midnight to noon rather than what would more properly be described as night-time. It is less easy to anticipate the effect, in Britain, of increasing or decreasing the proportion of institutional deliveries. The differences found are as likely to be due to selection of cases, in which event a change in practice would have no effect, as to attitudes to hospitalization. 
(5) Diurnal Cycle in Single Days Onset of Labour

At an earlier stage, we have noted that a single set of pooled data does not by itself provide adequate evidence of a diurnal cycle; but our analysis has indeed shown that the same diurnal pattern is manifest in pooled data of sub-groups referable to different calendar periods. We may submit the issue to a more exacting test by considering a succession of individual days. In the present study, there were available 66 continuous days in 1950 from August 1 to October 5. Unfortunately, the numbers in any one day were small, the average number of onsets per hour being only 1.4 ; and there is hence considerable scatter. Yet even such small numbers furnish corroboration for the view that there is a regular diurnal cycle. On 86 per cent. of the days, more than the expected number of labours started in the maximum 6-hour period, i.e. 11 p.m. to 5 a.m. A clearly defined peak appeared in 46 days, and of these peaks, 61 per cent. occurred in the same 6-hour period, the largest number being at 2 a.m. to 3 a.m.

Evidence supplied by such a consecutive series of days is amenable to scrutiny from another approach by recourse to the periodogram technique. We then consider the data as a series of 1,584 consecutive hours and seek for evidence of any periodicity. This forestalls any possible bias which might arise from pooling the data by days as has been done hitherto. Fig. 16 shows the result of a periodogram of oscillations at periods from 2 to 30 hours. The dotted lines indicate that some intervening values have not been determined. There is a minor period at 4 hours and multiples thereof. The main feature however is the 24-hour period standing out very sharply from neighbouring values. The examination of a consecutive series of hours does therefore substantiate, by a different method, evidence already presented for the existence of a diurnal cycle with respect to times of onset of labour.

\section{(6) Summary}

The author, no less than the reader, is well aware that this inquiry has raised many more questions than its outcome can answer. One reason for this is to be found in the limitation of hand processes. Owing to the complexity of the phenomena, more comprehensive and decisive conclusions would be justifiable only if based on more elaborate crossclassification, involving recourse to a much larger number of cases. Without mechanization, the labour involved in an inquiry planned on such a scale would be prohibitive. Unfortunately, few, if any, record systems (not excepting that initiated by the writer in Birmingham) allow for time of onset and of delivery as punched items. If it achieves no other result, the present investigation may provide

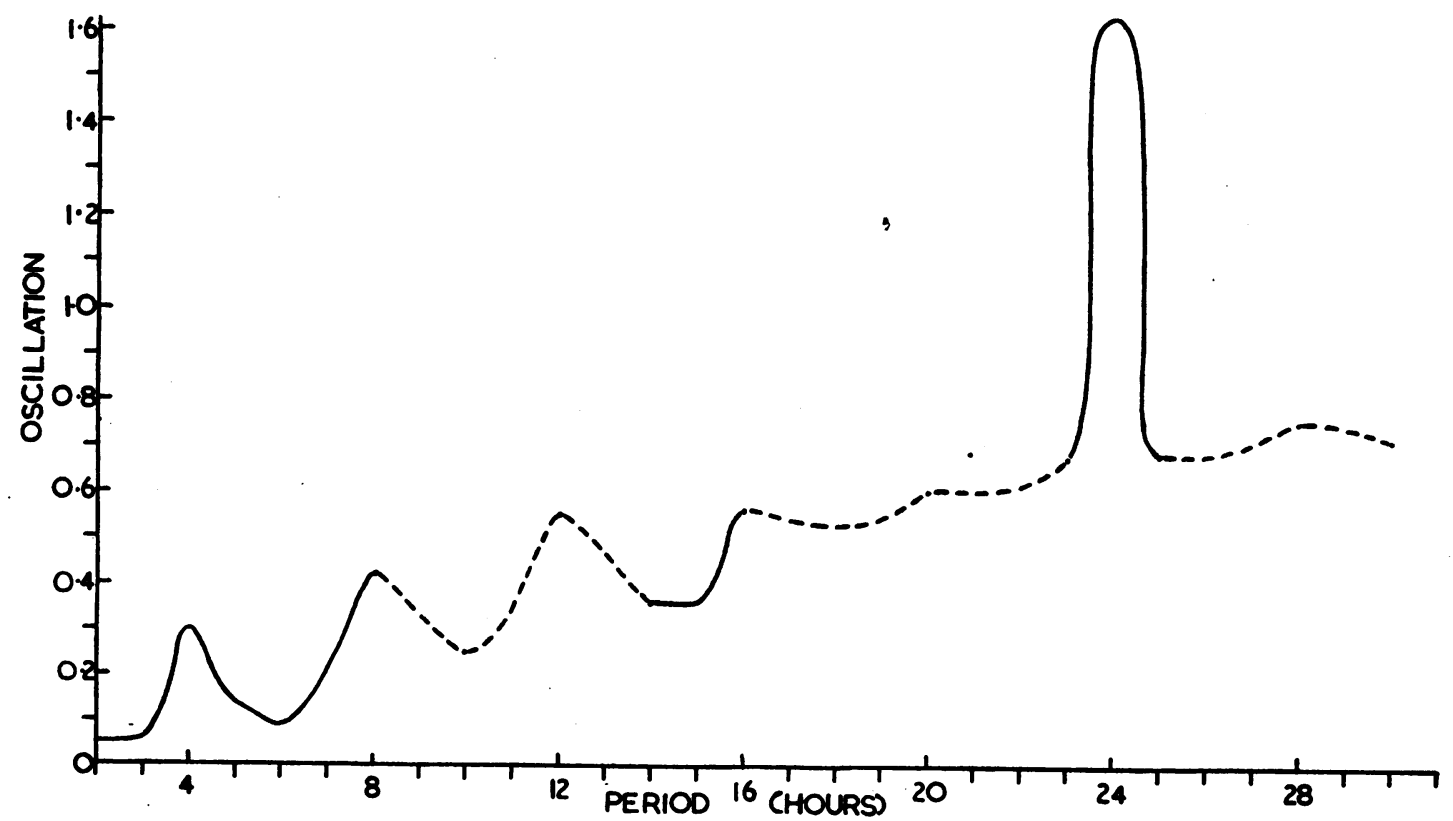

FIG. 16.-Periodogram of oscillation of times of onset of labour for periods of from 2 to 30 hours. 
justification for planning a mechanized study of the subject on a much bigger scale.

From the methodological standpoint, some points raised in what has gone before are relevant to many inquiries involving time. With respect to diurnal rhythm, we have seen that it is necessary to draw a sharp distinction between solar time and that of the socially calibrated clock. To forestall misinterpretation arising from failure to make this distinction, the data of this inquiry were grouped seasonally to facilitate study of changes with respect both to intensity and wave-length of light as well as to changes referable to the social calendar. Considerations which prompted this type of breakdown are relevant to any statistical inquiries exploring seasonal differentials as an aetiological clue. The main points which emerge from the results can be summarized as follows:

(i) Times of onset of labour and times of delivery were tabulated for over 16,000 live and still births occurring in the City of Birmingham in 1951 and 1952. Detailed analysis was confined to a group of selected live births, from which were excluded:

(a) those exhibiting any one of a described number of conditions likely to affect materially the onset or course of labour;

(b) all induced onsets and/or deliveries.

(ii) The selected cases showed a striking diurnal rhythm with respect to time of onset, the maximum being at or near $2 \mathrm{a} . \mathrm{m}$. to $3 \mathrm{a} . \mathrm{m}$. and the minimum at about 1 p.m. to 2 p.m. If night is defined as the 12 -hour period from 9 p.m. to 9 a.m., labour started at night in 62 per cent. of the selected cases. The diurnal rhythm was found in all the sub-classes of this group, though differences were seen in the steepness of the distribution and in the proportion of labours starting before the 2 a.m. peak.

(iii) Distributions of times of onset were steeper for primigravidae than for multigravidae and for domiciliary than for institutional births. Multigravidae show a higher proportion of onsets between 2 p.m. and 6 p.m.

(iv) Of seasonal differences, which are less clear cut than the foregoing, the data disclose relatively more onsets in the day-time in the winter months, and hence a flattening of the distributions referable to November, December, March, as compared with those referable to June, August, and September. Since distributions for cases referable to intervals equally spaced about the two equinoxes show no evidence of a peak-shift consonant with the change from Greenwich Mean Time to daylightsaving time (British Summer Time), we are entitled to exclude the activation of neurohumoral controls as an explanation of the diurnal periodicity. Our breakdown throws no direct light on the agencies contributory to the seasonal difference itself.

(v) The rejected cases and stillbirths showed much earlier onsets as well as a flatter distribution than the foregoing. The peak time of onset was 10 p.m. for rejected cases, and 9 p.m. for stillbirths.

(vi) As would be expected from the wide variation with respect to duration of labour, times of delivery are more evenly distributed throughout the 24 hours. For all selected cases, 55.6 per cent of the deliveries occurred in the 12-hour period 9 p.m. to 9 a.m., the peak delivery time being about 3 a.m.

(vii) The distribution of durations would result in an expected peak some hours later. It appears that durations are relatively more frequent both for primigravidae and for multigravidae when labour starts between 11 a.m. and 1 p.m., but are less so when it starts between 4 p.m. and 7 p.m. As a result of greater variation with respect to duration of labour, delivery times for primigravidae show less diurnal variation than do multigravidae, and are, in fact, approximately evenly distributed throughout the 24 hours. Rejected cases and stillbirths also show a more uniform distribution.

(viii) Delivery times of all live and still births show an excess of deliveries at night. The 12-hour period containing most deliveries is from 9 p.m. to 9 a.m. with 55 per cent. of births and the peak hour is 3 a.m. to 4 a.m. Results for Birmingham are compared with figures given for New York and Lancashire. The agreement between all three with respect to the proportion of births taking place at night is fairly close. Differences between Birmingham and Lancashire are explained by the greater frequency of first births in the latter district.

(ix) The results obtained suggest a tendency for normal labour to start more readily when the mother is at rest, if not actually asleep. Increasing severity of pathological conditions, as shown by the rejected cases and stillbirths, may be associated with a readier response to such emotional and nervous stimuli as are commonly believed to initiate labour.

The author acknowledges indebtedness to the Birmingham Maternity and Child Welfare Department for permitting access to the records.

\section{REFERENCES}

Charles, E. (1951). British Journal of Social Medicine, 5, 41.

- and Moshinsky, P. (1938). "Differential Fertility in England and Wales during the Past Two Decades". In "Political Arithmetic", ed. L. Hogben, chap. 3, pp. 106-160. Allen and Unwin, London."

Hill, A. Bradford (1948). "Principles of Medical Statistics", 4th ed. Lancet, London.

Lancashire County Council (1952). "Report of the M.O.H. for the Year 1950".

Registrar-General (1951). "Statistical Review of England and Wales for 1949". H.M.S.O., London.

Simpson, A. S. (1952). "Are More Babies Born at Night?", Brit. med. J., 2, 831 . 
APPENDIX TABLE A

TIME OF ONSET OF LABOUR-SELECTED CASES, BIRMINGHAM, 1950, 1951

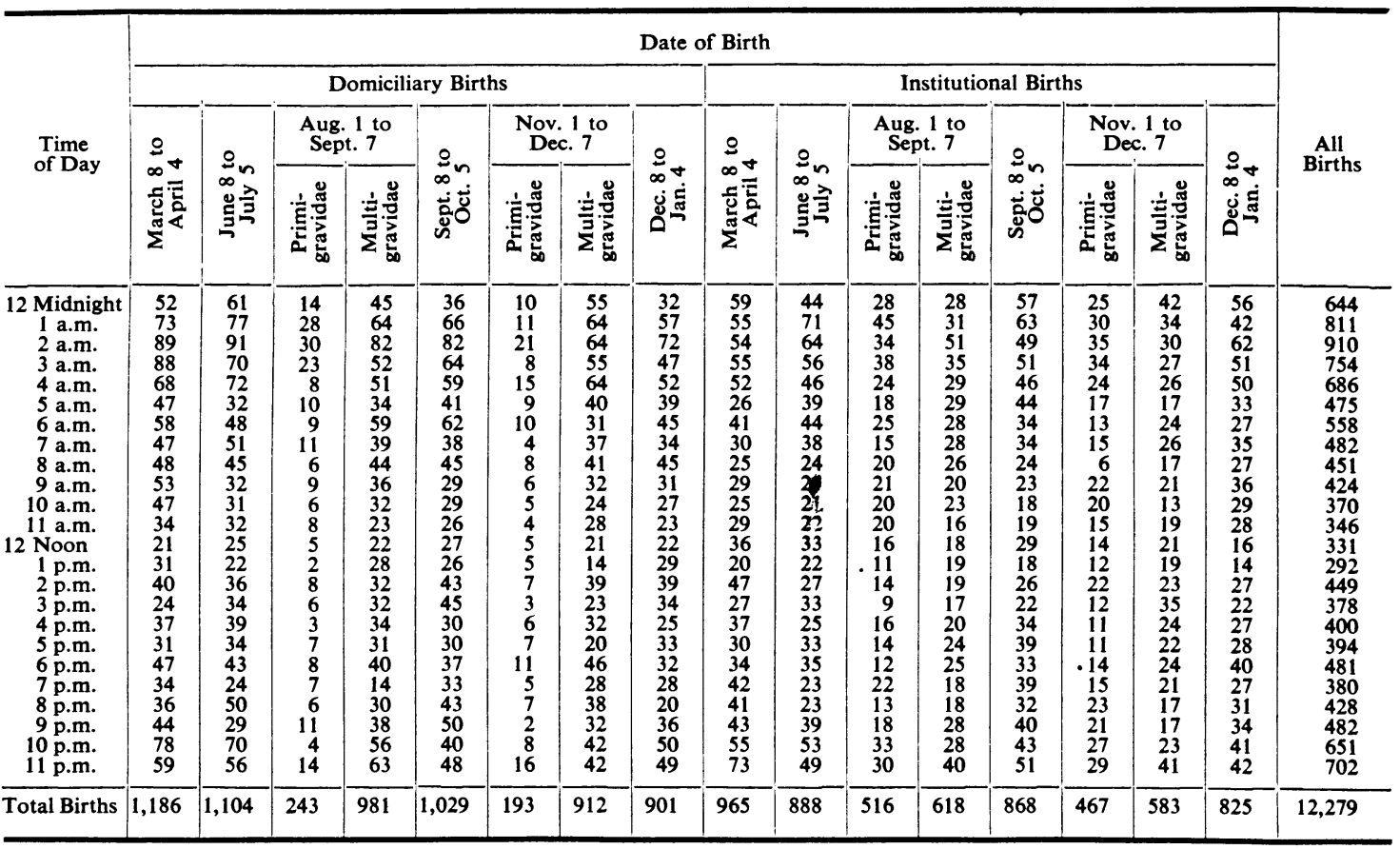

APPENDIX TABLE B

TIME OF DELIVERY-SELECTED CASES, BIRMINGHAM, 1950, 1951

\begin{tabular}{|c|c|c|c|c|c|c|c|c|c|c|c|c|c|c|c|c|c|}
\hline \multirow{4}{*}{$\begin{array}{l}\text { Time } \\
\text { of Day }\end{array}$} & \multicolumn{16}{|c|}{ Date of Birth } & \multirow{4}{*}{$\underset{\text { Births }}{\text { All }}$} \\
\hline & \multicolumn{8}{|c|}{ Domiciliary Births } & \multicolumn{8}{|c|}{ Institutional Births } & \\
\hline & \multirow{2}{*}{ 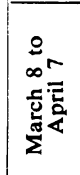 } & \multirow{2}{*}{ 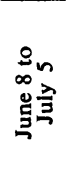 } & \multicolumn{2}{|c|}{$\begin{array}{l}\text { Aug. } 1 \text { to } \\
\text { Sept. } 7\end{array}$} & \multirow{2}{*}{ 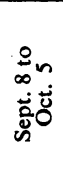 } & \multicolumn{2}{|c|}{$\begin{array}{l}\text { Nov. } 1 \text { to } \\
\text { Dec. } 7\end{array}$} & \multirow{2}{*}{ 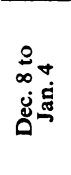 } & \multirow{2}{*}{ 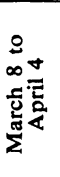 } & \multirow{2}{*}{ 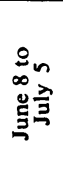 } & \multicolumn{2}{|c|}{$\begin{array}{l}\text { Aug. } 1 \text { to } \\
\text { Sept. } 7\end{array}$} & \multirow{2}{*}{ 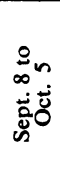 } & \multicolumn{2}{|c|}{$\begin{array}{l}\text { Nov. } 1 \text { to } \\
\text { Dec. } 7\end{array}$} & \multirow{2}{*}{ 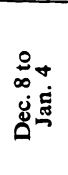 } & \\
\hline & & & 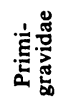 & 产聯 & & 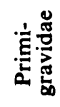 & 竞: & & & & 童惫 & 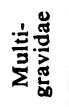 & & 它妾兽 & 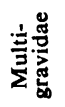 & & \\
\hline 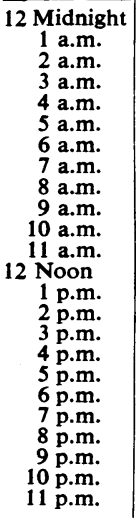 & $\begin{array}{l}41 \\
50 \\
70 \\
62 \\
71 \\
54 \\
67 \\
55 \\
60 \\
46 \\
42 \\
45 \\
34 \\
49 \\
44 \\
38 \\
46 \\
56 \\
43 \\
36 \\
44 \\
38 \\
41 \\
66\end{array}$ & $\begin{array}{l}54 \\
47 \\
59 \\
74 \\
58 \\
50 \\
60 \\
62 \\
56 \\
33 \\
41 \\
42 \\
45 \\
34 \\
40 \\
32 \\
34 \\
33 \\
47 \\
43 \\
48 \\
40 \\
48 \\
53\end{array}$ & $\begin{array}{r}8 \\
10 \\
10 \\
7 \\
10 \\
16 \\
11 \\
16 \\
10 \\
8 \\
9 \\
7 \\
13 \\
12 \\
10 \\
15 \\
99 \\
10 \\
10 \\
10 \\
7 \\
5 \\
7 \\
11\end{array}$ & $\begin{array}{l}45 \\
46 \\
68 \\
53 \\
55 \\
39 \\
43 \\
49 \\
39 \\
41 \\
36 \\
33 \\
39 \\
37 \\
27 \\
28 \\
40 \\
37 \\
29 \\
30 \\
40 \\
36 \\
33 \\
55\end{array}$ & $\begin{array}{l}38 \\
45 \\
56 \\
46 \\
52 \\
46 \\
48 \\
42 \\
52 \\
41 \\
42 \\
42 \\
38 \\
39 \\
35 \\
38 \\
41 \\
42 \\
39 \\
56 \\
41 \\
33 \\
41 \\
53\end{array}$ & $\begin{array}{r}4 \\
3 \\
4 \\
11 \\
10 \\
11 \\
8 \\
12 \\
9 \\
9 \\
11 \\
14 \\
6 \\
7 \\
8 \\
5 \\
9 \\
9 \\
3 \\
5 \\
6 \\
9 \\
8 \\
10\end{array}$ & $\begin{array}{l}36 \\
39 \\
49 \\
60 \\
49 \\
47 \\
47 \\
41 \\
41 \\
39 \\
31 \\
33 \\
29 \\
25 \\
33 \\
28 \\
28 \\
37 \\
36 \\
32 \\
24 \\
36 \\
40 \\
47\end{array}$ & $\begin{array}{l}25 \\
42 \\
43 \\
41 \\
48 \\
45 \\
48 \\
45 \\
40 \\
31 \\
35 \\
47 \\
30 \\
34 \\
36 \\
34 \\
36 \\
38 \\
40 \\
38 \\
30 \\
36 \\
30 \\
41\end{array}$ & $\begin{array}{l}42 \\
54 \\
52 \\
65 \\
50 \\
44 \\
42 \\
42 \\
28 \\
36 \\
36 \\
32 \\
39 \\
42 \\
33 \\
31 \\
39 \\
28 \\
41 \\
37 \\
31 \\
35 \\
39 \\
43\end{array}$ & $\begin{array}{l}42 \\
36 \\
37 \\
50 \\
49 \\
55 \\
39 \\
40 \\
35 \\
39 \\
30 \\
30 \\
44 \\
39 \\
26 \\
37 \\
25 \\
33 \\
30 \\
35 \\
31 \\
44 \\
27 \\
38\end{array}$ & $\begin{array}{l}14 \\
19 \\
18 \\
19 \\
21 \\
14 \\
22 \\
23 \\
24 \\
24 \\
23 \\
29 \\
22 \\
16 \\
28 \\
17 \\
29 \\
26 \\
22 \\
10 \\
17 \\
29 \\
25 \\
26\end{array}$ & $\begin{array}{l}23 \\
26 \\
33 \\
46 \\
33 \\
24 \\
24 \\
26 \\
24 \\
25 \\
25 \\
24 \\
28 \\
22 \\
23 \\
24 \\
21 \\
25 \\
18 \\
20 \\
18 \\
29 \\
25 \\
28\end{array}$ & $\begin{array}{l}44 \\
42 \\
37 \\
39 \\
37 \\
45 \\
47 \\
39 \\
36 \\
41 \\
35 \\
30 \\
34 \\
48 \\
35 \\
41 \\
33 \\
20 \\
32 \\
29 \\
27 \\
32 \\
34 \\
50\end{array}$ & $\begin{array}{l}18 \\
15 \\
20 \\
20 \\
20 \\
20 \\
28 \\
27 \\
19 \\
13 \\
17 \\
25 \\
17 \\
20 \\
17 \\
21 \\
22 \\
15 \\
17 \\
15 \\
25 \\
17\end{array}$ & $\begin{array}{l}31 \\
20 \\
34 \\
39 \\
33 \\
22 \\
27 \\
25 \\
28 \\
21 \\
15 \\
27 \\
19 \\
15 \\
25 \\
21 \\
23 \\
17 \\
24 \\
16 \\
20 \\
28 \\
25 \\
23\end{array}$ & $\begin{array}{l}45 \\
40 \\
35 \\
52 \\
43 \\
44 \\
47 \\
45 \\
38 \\
34 \\
24 \\
40 \\
29 \\
31 \\
23 \\
35 \\
25 \\
25 \\
25 \\
29 \\
22 \\
35 \\
30 \\
41\end{array}$ & $\begin{array}{l}510 \\
534 \\
625 \\
684 \\
639 \\
576 \\
608 \\
589 \\
539 \\
481 \\
452 \\
500 \\
466 \\
470 \\
443 \\
441 \\
459 \\
458 \\
454 \\
443 \\
421 \\
490 \\
475 \\
602\end{array}$ \\
\hline Total Births & 1,198 & 1,133 & 241 & 978 & 1,046 & 191 & 907 & 913 & 961 & 891 & 517 & 614 & 887 & 467 & 578 & 837 & 12,359 \\
\hline
\end{tabular}

